\title{
Les maïs natifs du nord, centre et sud du Mexique
}

Capital naturel ou patrimoine bio-culturel ?

The maize landraces of North, Center and South of Mexico: natural capital or biocultural heritage?

La biodiversidad de los maíces nativos: entre el patrimonio biocultural y el capital natural

\section{Elena Lazos-Chavero et Michelle Chauvet}

\section{OpenEdition}

Journals

Édition électronique

URL : https://journals.openedition.org/ethnoecologie/7260

DOI : $10.4000 /$ ethnoecologie.7260

ISSN : 2267-2419

Éditeur

Laboratoire Éco-anthropologie

Référence électronique

Elena Lazos-Chavero et Michelle Chauvet, « Les maïs natifs du nord, centre et sud du Mexique », Revue d'ethnoécologie [En ligne], Supplément 2 | 2021, mis en ligne le 25 novembre 2021, consulté le 20 décembre 2021. URL : http://journals.openedition.org/ethnoecologie/7260 ; DOI : https://doi.org/ 10.4000/ethnoecologie.7260

Ce document a été généré automatiquement le 20 décembre 2021.

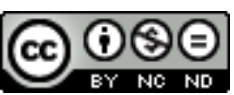

Revue d'ethnoécologie est mis à disposition selon les termes de la licence Creative Commons Attribution - Pas d'Utilisation Commerciale - Pas de Modification 4.0 International. 


\title{
Les maiis natifs du nord, centre et sud du Mexique
}

\author{
Capital naturel ou patrimoine bio-culturel ? \\ The maize landraces of North, Center and South of Mexico: natural capital or \\ biocultural heritage? \\ La biodiversidad de los maíces nativos: entre el patrimonio biocultural y el \\ capital natural
}

Elena Lazos-Chavero et Michelle Chauvet

\section{Introduction : La diversité des maïs}

1 L'importance du maïs comme patrimoine bio-culturel du Mexique est indiscutable; c'est l'aliment de base de tout repas mexicain. Il est à la fois l'empreinte et la réussite culturelle des peuples indigènes et métis tout en représentant le dénouement social et historique marqué autant par les joies que les tragédies. Tour à tour dieu et serviteur, il est source de nombreux biens et produits ainsi que de la concrétion de relations sociales. Il est le résultat de la domestication sur le territoire mésoaméricain, lequel constitue le centre d'origine et de diversification de sa culture (Wellhausen et al. 1951, Hernández-Xolocotzi 1985, Warman 1988, Boege 2008, Kato et al. 2009, Sandstrom 2010, Seefoó et Keilbach 2010, Oseguera 2010, CONABIO 2011). Comme le souligne Warman (1988: 1$)$, le maïs est

« inventé quotidiennement par les agriculteurs grâce à leur travail, à leurs savoirs,

à leur respect et vénération, à leur passion, et à leur vie qui tourne autour de cette plante. Ils l'inventent avec une obstination têtue ».

Le maiis en tant que patrimoine bio-culturel est donc le résultat de cette réinvention jour après jour à travers le travail, mais aussi grâce à une série de savoirs agroécologiques essayés ici et là tout au long des générations d'agriculteurs qui se battent pour défendre cette plante, source de leur vie. Cependant, depuis quelques décennies, planent sur elle des menaces qui viennent des politiques macroéconomiques 
visant principalement la génération de gains et rentes extraordinaires. Celles-ci ont eu pour conséquence de transformer les priorités d'investissement des États et de les rendre défavorables à la production agricole familiale par le biais de dynamiques institutionnelles provoquant la marginalisation d'une grande partie des familles paysannes et indigènes. Malgré cela les 64 races de maïs natifs recensées, dont 59 sont reconnues originaires du Mexique, ont été conservées jusqu'à aujourd'hui (Montañez y Aburto 1979, Centro de Investigaciones Agrarias 1980, Warman y Montañez 1982, Hewitt de Alcántara 1992, Nadal y Wise 2005, Wise 2007, Kato et al. 2009, Perales 2010, Perales y Golicher 2014).

3 Ces dynamiques institutionnelles s'expriment de manière très diverse au niveau local et changent selon les périodes marquées par les contextes socioéconomiques et politiques. En outre, les formes de la production de l'agriculture paysanne ainsi que les relations sociales, politiques et économiques leur servant de socle varient fortement selon les régions; dans certaines zones, les politiques agricoles provoquent un changement dans l'usage des sols, faisant passer d'une agriculture de parcelles de maïs $\left(m i l p a^{1}\right)$ à un élevage extensif; dans d'autres, elles mènent à la surexploitation des terres sur les pentes occasionnant une forte érosion; et dans d'autres encore, les agriculteurs continuent à cultiver des parcelles de maïs variés (milpas diversifiées). L'exemple de Zinacantán, municipalité appartenant aux Altos de l'État du Chiapas et peuplée en grande majorité de Tzotzil, est emblématique des changements du rôle joué par le maïs dans la communauté. Avant les années 60, la majorité des familles vivaient des parcelles de maïs hautement diversifiés; dans les années 70, la majorité des producteurs s'étaient convertis en main d'œuvre salariée et la culture du maïs indigène (milpa) jouait un rôle mineur dans la vie des familles; avec la crise des années 80 , les Zinacantèques revinrent à la culture et usages traditionnels du maïs (milpa); et vers les années 90, le maïs retourne à une moindre importance dans l'alimentation de la communauté (Collier 1992). Enfin, travailler « ensemble», signifiait que tout le groupe domestique participait à la culture du maïs indigène (milpa), que tous s'alimentaient et s'habillaient avec le produit de cette agriculture, puis ils passèrent au travail « séparé ", car les jeunes avaient expérimenté une indépendance économique dans le travail salarié, et leur vie ne se centrait plus autour de la production et de la consommation familiales du maïs (Collier 1992). Cette histoire est représentative de ce qui se passe dans de nombreuses régions (Bellon 1991, Lazos 2011, Morales et al. 2017, Bellon et al. 2018, Pérez Ruiz 2018).

4 Ces processus se sont intensifiés au cours des trois dernières décennies du fait des politiques agricoles, qui n'ont pas seulement découragé les productions familiales mais également ont ouvert les portes de la production et du commerce aux compagnies transnationales (semencières, fabricants de machine, producteurs d'agrochimie et de fertilisants, distributeurs, entreprises de conditionnement, fournisseurs d'ensemble agro technologiques). Depuis la signature de l'ALENA (TLCAN), on peut parler d'un tournant majeur qui menace la production paysanne familiale à travers trois processus : la marchandisation, la financiarisation ${ }^{2}$ et l'énergétisation de l'agriculture incluant, en outre, la privatisation des ressources génétiques ${ }^{3}$. Cette privatisation des ressources génétiques compromet non seulement les droits des communautés rurales d'être, premièrement, considérées productrices d'agro-diversité, mais également de pouvoir produire correctement. Elle met aussi en péril les droits à l'alimentation de la population et donc, la sécurité alimentaire du pays. Les importations agro-alimentaires 
sont passées de 24 à $46 \%$ de la demande nationale dans les deux dernières décennies et elles continueront à augmenter jusqu'à 2030, selon les estimations du Département de l'Agriculture des États-Unis, le Mexique importerait alors $80 \%$ de son alimentation (Suárez 2013). Cette dépendance a été aggravée par la pression exercée par l'industrie biotechnologique (agroalimentaire), pour faire accepter les semis de maïs transgénique dans le pays, ce qui présente un réel risque de perdre la diversité des maïs par la contamination génétique (Quist et Chapela 2001, Piñeyro et al. 2009).

C'est avec ce panorama de grandes incertitudes et de fortes transformations, que l'objectif de notre article est, d'un côté, d'analyser l'importance de faire connaître la biodiversité des maïs natifs comme faisant partie du patrimoine bio-culturel, et résultant des multiples processus contradictoires socio-économiques, politiques, culturels et écologiques; et d'un autre côté, de comprendre la diversité des mosaïques agricoles du nord, du centre et du sud du pays pour établir les critères bio-culturels et pouvoir déclarer que tout le territoire mexicain est le centre d'origine et de diversification du maïs ${ }^{4}$. Dans ce sens, il est impératif d'approfondir la grande hétérogénéité des connaissances et de la signification du maïs dans les communautés rurales comme patrimoine afin de proposer des alternatives viables sur la base de l'agro-diversité qui apporterait le bien-être social et peu à peu une construction de l'autonomie alimentaire.

6 Ainsi, l'une des meilleures actions pour analyser la distribution des maïs natifs au Mexique a été le «Projet global des maïs natifs » financé par la Commission Nationale pour la Connaissance et l'Usage de la Biodiversitté (CONABIO), auquel collaborèrent plus de 200 chercheurs de 65 institutions académiques et de recherche. Son objectif était d'assembler l'information agronomique sur les races de maïs natifs, leur distribution dans tous les États fournissant les bases écologiques et agronomiques nécessaires pour établir quels sont les centres d'origine et la diversité des races. Ces recherches ont été réalisées de 2004 à 2011 ; elles ont actualisé la base des données sur les maïs natifs, qui avait été établie par de multiples collectes tout au long du $\mathrm{Xx}^{\mathrm{e}}$ siècle (Kato et al.2009, Perales et Golicher 2014) (Figure 1). Ces dernières collectes (2004-2011) furent conçues principalement afin de remplir les objectifs mentionnés plus haut, mais quelques équipes obtinrent également des données socio-économiques et culturelles. Même si celles-ci sont incomplètes, l'importance de l'information qu'elles apportent au niveau de chaque État mérite une étude spécifique. 
Figure 1 : Mexique : localisation géographique des collectes de maïs (2006-2010)

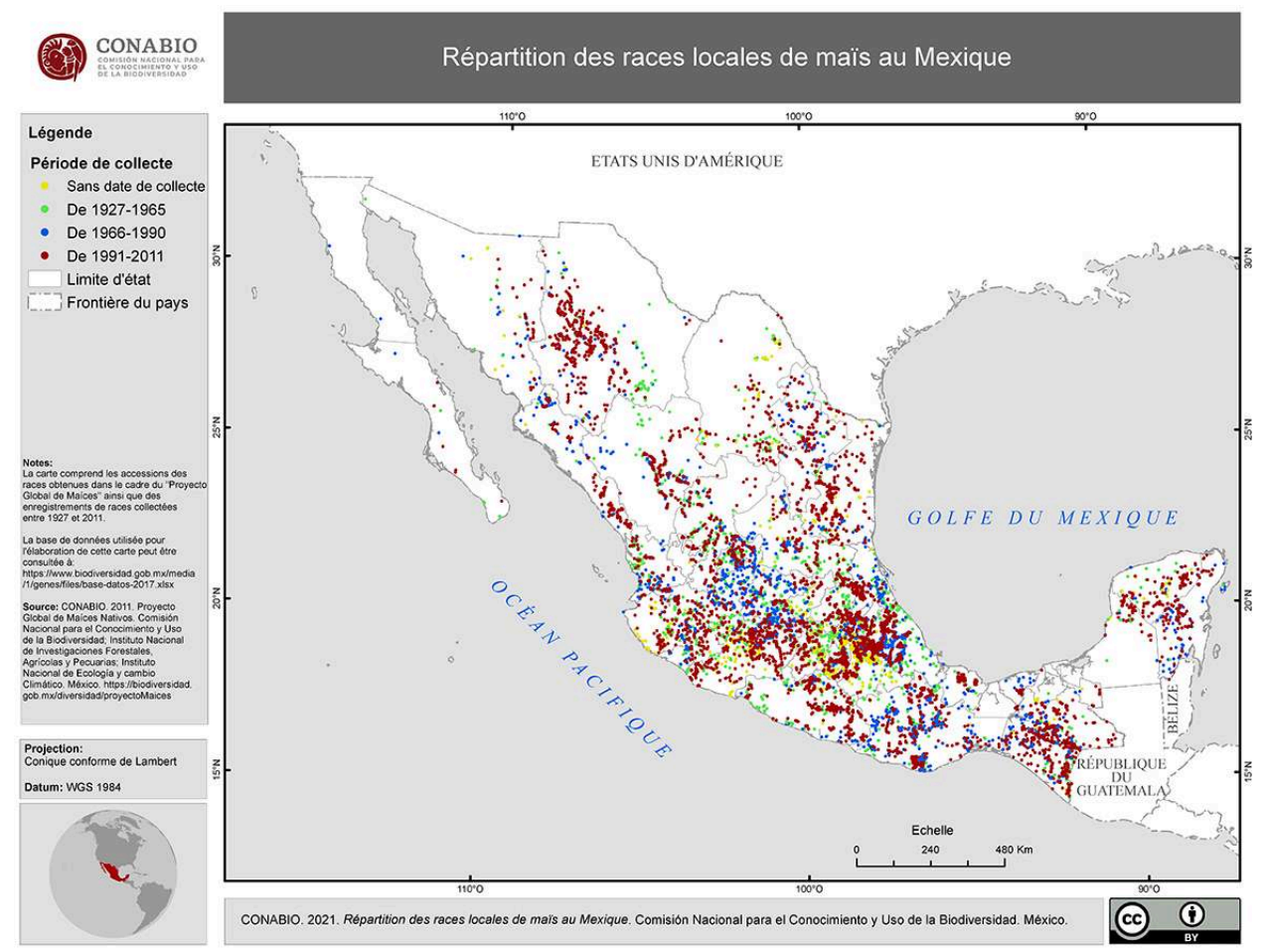

Source : CONABIO, 2010. Dessin O. Oliveros

7 Les mosaïques agricoles si hétérogènes au Mexique amènent toute une série de questions sur la conservation des maïs natifs comme patrimoine bio-culturel : Quels sont les facteurs écologiques, sociaux, culturels, économiques et politiques qui ont influencé la distribution des maïs natifs? Quel est le poids de chacun de ces facteurs dans leur distribution? Pourquoi y a-t-il des races largement distribuées et d'autres avec une diffusion plus restreinte? Ces questions ont reçu des réponses à la fois complémentaires et contrastées à l'aide de divers travaux tant au niveau régional que national (Howes et Chambers 1980, Brush 1986, Mapes 1987, Brush et al. 1988, Bellon 1991, Gadgil et al. 1993, Terán et Rasmussen 1994, Taba 1995, Perales et al. 2003, Lazos 2008, Seefoó et Keilbach 2010), mais nous n'avons pas de statistiques nationales différenciées des races de maïs permettant de répondre à cette question au niveau national. Les distributions nationales de surfaces cultivées, les rendements par race de maïs, les caractéristiques techno-agricoles, les interrelations entre les différences écologiques et géomorphologiques des régions avec les diverses races ne peuvent être calculées par manque de données. Un exemple : d'octobre 2015 à septembre 2016, 25,7 millions de tonnes de maiis ont été produites, dont 22,3 correspondent au maiis blanc et le reste au jaune ; cependant, les races de maïs natifs ne se différencient pas et elles sont toutes cataloguées comme maïs blanc pour la consommation humaine (SIAP 2016). En effet, toutes les races entrent dans le pool de maïs sous la perspective simplement productiviste et commerciale. Ceci reflète le peu d'importance accordée autant à la connaissance de la distribution des maïs natifs dans le pays, qu'à l'établissement de politiques pour leur conservation et leur production par les instances gouvernementales. Les collectes réalisées depuis les années 40 (Wellhausen et al. 1951, Hernández-Xolocotzi 1985, Fenzi 2017) faisaient partie des premiers efforts 
internationaux pour collecter le matériel génétique dans les centres d'origine pour les mettre ensuite dans des «banques de gènes » (ex situ) afin de fournir du matériel en vue d'en sélectionner de nouveaux (Fenzi et Bonneuil $2016: 74$ ). Cependant, ces collectes ont été discontinues, et encore aujourd'hui, malgré les efforts de la CONABIO, on ne possède pas une carte complète de la distribution des maïs natifs au Mexique (Figure 1).

Devant les menaces de la libération commerciale du maïs transgénique, CONABIO s'efforce de stimuler les collectes de maïs natifs dans le but d'actualiser l'information sur les maïs et des espèces sauvages apparentées pour établir les centres d'origine et de diversification du maïs (en accord avec les articles 86,87 et 88 de la Loi de biosécurité des organismes génétiquement modifiés). Dans le but également de visualiser l'importance socio-économique et culturelle de la production de maïs natifs, CONABIO nous a demandé d'analyser l'information accompagnant les collectes réalisées entre 2004 et 2011 (Lazos et Chauvet 2012). Nous présentons ici une partie de ces résultats.

Dans la première partie de cet article, nous réfléchirons sur la double valeur qu'ont les maïs natifs comme biens aliénables et inaliénables. Cette analyse nous permettra de réfléchir sur les possibilités, mais aussi sur les défis socio-politiques, économiques et culturels pour considérer les maïs natifs comme part fondamentale du patrimoine bioculturel des agriculteurs, puisqu'ils circulent, comme biens aliénables, entre les familles et les communautés pour former la part fondamentale de leur alimentation, mais aussi, comme biens inaliénables, ils se transmettent de génération en génération renforçant les symboles, les signifiants et les savoirs sur la culture du milpa.

Les comparaisons socio-économiques et culturelles des collectes de maïs natifs, exposées dans la seconde partie de l'article, nous permettront de comprendre la valeur et le rôle que jouent encore les maïs dans la vie des agriculteurs de notre pays. En outre, le diagnostic des particularités régionales des maïs natifs, nous fournit les dimensions qui favorisent ou menacent sa conservation.

11 S'il est bien certain que le patrimoine bio-culturel englobe l'ensemble des processus dynamiques de la domestication continue de la flore et de la faune entretissées symboliquement en mosaïques socio-culturelles par les populations locales sur des territoires particuliers, nous nous centrerons pour comprendre ce que signifie la transmission et la conservation des maïs natifs au nord, au centre et au sud du pays en nous basant sur les collectes réalisées par les diverses équipes mises en place par CONABIO. À partir de ces informations écrites rassemblées lors des collectes, nous chercherons à comprendre les aspects socio-économiques et culturels décrits. La compréhension de ces dynamiques nous permet d'affirmer que la conservation du patrimoine du maïs est un processus bio-culturel qui procède de dynamiques contradictoires menaçant continuellement l'existence-même des maïs natifs avec leurs valeurs sociales et culturelles et leurs savoirs associés (Lazos et Chauvet 2012).

\section{Restaurer un patrimoine bio-culturel ou formaliser un capital naturel ? Les maïs comme biens aliénables et inaliénables}

Une partie de notre culture est formée par une série d'habitudes, de savoirs, d'idées, de normes, règles, valeurs et traditions; une autre partie, par des biens et des symboles qui s'échangent et génèrent les réseaux signifiants et identitaires des populations 
(Geertz 1995). Ces biens, selon Marcel Mauss, se divisent en deux catégories : a) les biens aliénables continuellement insérés dans l'échange social basé sur la réciprocité et la circulation et $b$ ) les biens inaliénables qui se transmettent et s'héritent au fil des générations (Mauss 1990). Ainsi, la culture représente les diverses formes d'échange de biens, habitudes, savoirs et valeurs, et leur transmission de génération en génération, construites sur l'héritage partagé des mécanismes d'adaptation, d'intégration, de confrontation et de transformation de la nature pour fournir les ressources nécessaires à la subsistance (Mauss 1990, 1950, Ribeiro 1990). C'est la façon d'être, de penser, de symboliser et de se comporter d'un peuple, qui le distingue des autres, et qui forme les identités culturelles. Une part importante de ces flux d'échange et de cet héritage est la culture alimentaire, laquelle est configurée par les semis, l'environnement de la région, les produits alimentaires transformés, les saveurs, les goûts, les manières de les cuisiner et de les consommer, ce qui crée de réseaux sociaux signifiants qui structurent cet héritage (Lévi-Strauss 1965, Katz 1996, Camou 2008, Contreras 2008).

13 Il est, pour les Mexicains, un bien qui nourrit toutes leurs cultures (Esteva 2003) ; c'est un bien autant aliénable qu'inaliénable. Il entre dans les circuits de don et contre-don des cultures mésoaméricaines comme un objet d'échange et de réciprocité, mais également il constitue un héritage bio-culturel dans la transmission de génération en génération tout comme un bien, avec ses savoirs et ses pratiques, avec ses symboles et ses valeurs. Pouvons-nous alors considérer que le maïs fait partie du patrimoine bioculturel des Mexicains? Le patrimoine implique la notion de collectivité, sa possession est maintenue par un groupe social, en général traditionnellement organisé ou conceptualisé par la parenté (Ferry 2002 : 331) ou par la culture des populations natives (Boege 2008, Argumedo n.d.). Il fonctionne selon une série de pratiques qui restreignent l'échange parce qu'on le considère idéalement inaliénable ; il n'appartient à aucun être humain en particulier. Sa possession, son accès et sa mise en action restent sous le contrôle du groupe social qui le réclame, parce qu'il représente des systèmes de valeurs collectives fondées sur la garde communautaire. La notion de patrimoine bio-culturel reflète aussi l'historicité et la façon dont les peuples pensent la nature appelée «la Terre Mère » ou la «Pachamama » (Rist 2002, Boege 2008, Houtart 2014). Ces biens et valeurs, qui englobent les ressources biologiques depuis le micro (génétique), jusqu'au macro (paysages et territoires), aux traditions, pratiques et savoirs dont hériteront les générations futures (Ferry 2002).

14 Le patrimoine inclut également les règles et les formes de comportement envers la nature et celles établies par les sociétés indigènes et métisses; ces règles sont acceptées en tant que droits et responsabilités entre les populations et la nature. Ils sont appelés «droits consuétudinaires" (Argumedo n.d.). Le patrimoine bio-culturel se définit comme étant l'ensemble de tout l'environnement (biotique et abiotique) selon sa richesse et selon les patrons culturels. Cela concerne tout particulièrement le patrimoine agricole basé sur la diversité biologique domestiquée, tolérée, induite, protégée et à l'état sauvage avec son germoplasme développé et/ou adapté localement (Boege 2008: 5-7, Casas et al. 2014). Ces pratiques génèrent des savoirs, lesquels se nourrissent des interactions et des perceptions de la nature avec les systèmes symboliques des rituels et des mythes d'origine (Ingold 1992, Ellen \& Fukui 1996).

Plus amplement, la notion de patrimoine inclut le patrimoine national, lequel est établi par une collectivité entière et diverse d'un pays. Au Mexique, le patrimoine national est resté celui promu par la Constitution de 1917 ; il se définit comme étant l'ensemble des 
ressources du sous-sol, des terres communales et des propriétés culturelles placées sous la juridiction des organisations locales et nationales. Mais le patrimoine national n'est pas seulement décrit dans la constitution et autres textes juridiques, il est aussi

«présent dans la société, puisqu'il y existe comme un ensemble de représentations largement partagées qui se réfèrent à certains biens (pétrole, minéraux..., pyramides...) qui ont une certaine force normative pour tous les membres de la société sous la forme et la structure d'un mythe » (Azuela 2009 : 54).

Ainsi, la

«principale fonction du patrimoine national en tant que mythe est d'inclure symboliquement les individus de la communauté nationale, au moyen de l'idée qu'il existe un catalogue des biens qui appartiennent à tous les Mexicains " (Azuela 2009 :54). Cette inclusion serait le «noyau de notre régime patrimonial en tant que fait social» (Azuela 2009 : 54).

17 Les maïs, comme l'argent, dans le cas de l'étude des mines de Ferry (2002), sont considérés comme patrimoine avec la notion de propriété inaliénable, puisqu'on réaffirme qu'ils sont considérés comme étant les possessions des générations passées et que l'on a obligation de les transmettre à ses enfants et petits-enfants. Les adaptations imprégnées dans les nombreux maïs natifs aux conditions climatiques ainsi que territoriales et aux diversifications spécifiques pour les usages, les objectifs productivistes et la consommation résultent du travail et des savoirs cumulés des générations passées. Dans le cas des mines, l'argent a le sens, d'un côté, d'être un bien qui, si on s'en préoccupe, donne du travail aux générations futures, et d'un autre côté, d'être un lieu historique enraciné dans la culture minière, ce qui lui donne un sens de possession inaliénable (Ferry 2002).

Il pourrait exister une contradiction entre un bien aliénable qui est en même temps inaliénable. Cependant, cela s'est résolu théoriquement, à l'aide du concept de réciprocité, qui convertit en une forme d'échange de possessions inaliénables pour garantir son retour et donc, sa survivance, ce que Weiner a appelé le «paradoxe de posséder pendant qu'on donne » (Weiner 1992).

L'usage du concept de patrimoine se comprend également en ce qu'il est production et travail. Dans le cas de la mine d'argent, les personnes de la coopérative ont décidé d'exploiter la mine de façon non intensive, c'est à dire, qu'ils travaillent en dessous de $50 \%$ de leur capacité. Ceci aux yeux de n'importe quel actionnaire représente un manque d'efficacité et une perte de capital ; mais pour ceux de la coopérative, c'est prévoir le futur. "Il serait très simple de mener une exploitation intense, mais la modernisation ne donnerait pas de travail pour longtemps $»^{5}$ (El Nacional, Diciembre 18, 1991 déclaration de l'un des directeurs de la coopérative cité par Ferry (2002: 339)). Dans le cas du maïs, les familles paysannes organisaient leur travail selon les règles de sa culture. Le cycle agricole non seulement structurait le travail de la famille pendant l'année, mais ordonnait aussi le cycle des fêtes et la vie symbolique de la communauté. Ces pratiques, croyances et cosmovisions se configurent continuellement de génération en génération (López Austin 1992, Celestino 2004, Sandstrom 2010). Sur cela repose le statut fondamental du patrimoine.

Dans le cas du maïs, ce bien, également, est le fruit d'adaptations, de transformations, de savoirs et pratiques et l'on doit s'en occuper pour le transmettre aux générations suivantes, mais il est aussi le fruit d'un territoire qui lui donne un sentiment d'appartenance et d'identité. Par exemple, le maïs Jala est l'orgueil des agriculteurs de cette petite communauté de Nayarit et de quelques communautés wirikutas du Jalisco, 
ce qui offre à ces populations les éléments distinctifs de leur identité. Ainsi les semences des maïs natifs s'échangent dans la communauté, ou la région, pour garantir l'alimentation, car les races des maïs sont associées à un territoire (Benz et al. 2007) Les facteurs écologiques sont les principaux moteurs de la diversité des races de maïs, mais les facteurs socioculturels ont également joué sur la distribution et la structure des populations de maïs (Anderson 1947, Brush \& Perales 2007). L'Isthme de Oaxaca se caractérise, par exemple, par la culture de la race Zapalote Chico pour la fabrication de totopos ${ }^{6}$.

21 En même temps, les communautés milperas survivent grâce à l'autoconsommation de leur production, pour une part, mais aussi grâce à l'échange du maïs comme marchandise. Comment conceptualiser inaliénabilité, échange et production valorisée du maïs lui-même? En premier lieu, il est incompréhensible pour un paysan milpero possédant des terres de ne pas cultiver son maïs, cela signifierait se transformer en producteur commercial, éleveurs du bétail bovin, journalier ou en travailleur urbain. Les fortes oscillations de sa production et les prix établis en dessous des coûts de sa production ont provoqué soit le remplacement de milpas par des cultures commerciales ou par l'élevage bovin, soit la migration rurale dans les trois ou quatre dernières décennies. Dans ce processus, le maïs peut agir comme une pure marchandise, c'est-àdire un objet circulant librement sur un marché international. Mais en même temps, quand il est cultivé depuis des générations et sa culture ritualisée, il s'établit alors une relation spécifique entre les agriculteurs et leur milpa qui est ressentie comme inaliénable. Ainsi, le maïs joue-t-il autant comme une possession inaliénable en termes de savoirs, pratiques, cosmovisions et valeurs symboliques qu'une marchandise échangeable participant au marché international. En outre, ce patrimoine communautaire est basé sur le travail, qui forge continuellement un patrimoine familial. Clairement, hommes et femmes travaillent pour le bien des membres de leur propre groupe domestique. Les familles planifient la production pour maximiser leurs options, cherchant à augmenter les possibilités de commercialisation (Collier 1992, García-Barrios \& García-Barrios 1992, Sandstrom 2010).

«Quand les habitants de Amatlán bavardent entre eux, les sujets qui les intéressent sont la politique locale et les commérages, mais avant tout, [...] l'agriculture, l'inflation des prix et les meilleures façons de profiter du système » (Sandstrom $2010: 270)$.

Dans cette optique, la culture des maïs forge 1) un patrimoine familial dépendant de la récolte, des prix, et influant les conditions de vie de la famille;2) un patrimoine communautaire dépendant de plusieurs populations et races de maïs avec leurs diverses adaptabilités à la sécheresse, aux vents, aux sols et aux changements microclimatiques; et 3) un patrimoine national, représentant un héritage de ressources phytogénétiques formé au long de centaines d'années sur tout le territoire du pays.

Forger un patrimoine communautaire de maïs n'est pas comme constituer une économie communautaire. Cela ne présuppose pas que les droits agraires s'attribuent communautairement, ni que soient résolus les conflits à l'accès et au contrôle des terres et biens naturels. Chaque famille contribue avec son héritage en maïs au pool communautaire, quand elle cultive une association de maïs sur ses parcelles. Les semis ainsi que l'échange des graines et semences forgent, dans certains villages, ce patrimoine communautaire qui est également renforcé par le partage de pratiques agricoles (propice aux demandes et aux remerciements), de prières, de la participation familiale et collective aux rituels et à la cosmovision (Celestino 2004). À Tetelcingo, les 
13 et 14 septembre se célèbre la fête de Xilocruz, dédiée à la croix de jilote autrement appelé maïs tendre. La majorité des familles commencent à préparer collectivement l'offrande. Les croix dites des champs et des quatre collines sont amenées à l'église où elles reçoivent des offrandes (courges, maïs tendre, fleurs, pastèques, melons). Les agriculteurs encensent ensemble leurs milpas, discutent avec les divinités de l'eau et de l'agriculture afin que « tout aille bien lors de cet échange entre les dieux, la milpa et les hommes » (Celestino 2004 : 148-149).

Cependant, on parle de l'ensemble des maïs comme d'un capital naturel du Mexique (CONABIO 2010). En ce sens, on ne les considère plus comme un bien interchangeable ni comme une provision héréditaire, mais seulement comme une part intégrante du processus productif. Ainsi, les maïs ont des prix et des coûts et si on les conserve, c'est parce qu'économiquement, ils vont être avantageux. Par exemple, depuis une décennie, le maïs bleu a connu une forte augmentation de sa demande dans le centre du pays dû à son utilisation alimentaire et comme teinture de tissus (une entreprise japonaise à Tlaxcala). Cela a entraîné un accroissement des superficies cultivées puisque les producteurs sont assurés de vendre ce maïs à un meilleur prix que d'autres variétés d'autres couleurs.

Au début des années 1990, des économistes de l'environnement ont créé le concept de capital naturel (Costanza \& Daly 1992) comme étant l'ensemble des stocks de la nature produisant un flux équitable de biens de grandes valeurs, surtout économiques, et les services utiles tout au long des temps. Cet inventaire naturel génère différents types de flux de produits ou de biens, de services ou de bénéfices indirects et une conservation de valeurs (Lele et al. 2013). Par exemple, une réserve forestière fournit un flux de nouveaux arbres, un réservoir d'eau et/ou une source de dioxyde de carbone. Ces services nommés services écosystémiques par Daily (1997) ont été définis comme étant les conditions et les processus par lesquels les écosystèmes naturels, et les espèces qui les composent, satisfont les besoins des sociétés et offrent un bien-être humain. Dans cette perspective, Costanza et d'autres auteurs (Costanza et al. 1997) ont publié « The value of world's ecosystem services and natural capital ", étude pionnière de la valorisation des services écosystémiques. Les auteurs ont estimé la valeur économique de 17 services écosystémiques en 13 biomes au niveau international. Les résultats suggèrent que, au niveau mondial, les écosystèmes génèrent environ 33 trillions de dollars par an. Ainsi, le concept de capital naturel commença à se développer de telle façon que l'environnement peut être inclus dans les calculs économiques (Boyd \& Banzhaf 2007), et que la nature est conçue comme un capital qui doit être préservé, conservé pour le développement économique (Gómez-Baggethun \& de Groot 2007). On en vient même à considérer la conservation de ce capital naturel comme important parce qu'il peut éviter les gaspillages extraordinaires provoqués par les ouragans (Akpan 2017).

Depuis la fin des années 2000, de nombreuses critiques ont été soulevées par cette focalisation seulement économique de la biodiversité ; ainsi l'étude de l'Économie des Écosystèmes et de la Biodiversité (TEEB-The Economy of Ecosystem and Biodiversity) a démontré que le concept de capital naturel ne peut être vu seulement depuis l'écologie et l'économie, mais qu'il doit également être compris en termes sociaux et culturels. À partir de cette période, plusieurs études ont développé ces idées.

27 Au Mexique, le projet Capital naturel du Mexique, initié en 2005, avait pour objectif d'identifier les options de conservation et les usages équitables de la diversité biologique, avantageuses pour les populations locales et d'avertir les décideurs que 
modifier un quelconque écosystème a des aspects positifs et négatifs qui doivent être équilibrés.

«Les écosystèmes et leurs services constituent un capital comparable aux capitaux financiers et d'infrastructure d'une nation [...] Le Capital naturel du Mexique représente un grand potentiel pour le développement et la production de bénéfices pour toute la population » (Sarukhan 2008, Vol. I, 9).

Assigner un prix à la nature et la considérer comme une sorte de capital de conservation, n'est qu'une vision mercantile d'une durabilité fragile, où la biodiversité est supposée être au service de l'humanité, mais on lui nie sa valeur intrinsèque indépendamment de la valorisation humaine.

« Ces aspects rendent infondé l'utilisation du concept de capital comme un élément fondamental de description et de valorisation de l'ensemble des éléments et processus de la nature » (Gudynas $2000: 11)^{7}$.

Un des inconvénients de ce concept est de considérer que donner une valeur monétaire aux écosystèmes contribuera à leur conservation car si on ne les considère que comme une inversion, cela n'assure pas la protection de leur biodiversité, puisqu'elle dépendra de ce que les gens ou les gouvernements sont prêts à payer pour elle (Gudynas 2000).

En ce sens, quand on se réfère aux maïs comme capital naturel, on considère uniquement leur part économique et matérielle. Cela entraîne que leur conservation soit seulement mesurée par les avantages économiques de sa culture. Depuis environ 20 ans, les maïs natifs sont entrés dans le circuit économique pour leur valeur culturelle (i.e. le marché de la tortilla gourmet ou du repas mexicain gourmet, gastronomique). En échange, quand on le représente comme patrimoine bio-culturel, le maïs reflète tout un monde de connaissances, symboles, identités, territoire ; mais en même temps, il trouve son importance également comme un bien interchangeable dans les schémas de réciprocité et pas seulement comme un bien aliénable soumis aux lois du marché international.

31 En ce sens, la Red de Maíz Criollo (réseau de maïs natifs) du Chiapas, avec l'aide d'associations civiles et de mairies, a travaillé pour inclure le système milpa à l'Inventaire du Patrimoine Culturel Immatériel du Mexique, ce qui fut accepté par la Commission Nationale du Patrimoine Culturel Immatériel ${ }^{8}$. Cela constitue un premier pas vers sa reconnaissance au Patrimoine Culturel de l'Humanité devant l'Organisation des Nations Unies (Carrillo 2013). Cependant il faut réfléchir aux implications que cette action peut avoir sur la conservation de l'identité et les bénéfices possibles qu'en peuvent tirer les communautés, étant donné que d'autres expériences de patrimonialisation de biens tangibles et intangibles, loin de réussir, ont dérivé vers leur commercialisation au bénéfice d'agents politiques ou privés et non pour la sauvegarde du Patrimoine Culturel Immatériel (Sevilla 2017).

32 C'est pour cette raison que les maïs doivent être défendus comme patrimoine communautaire par les familles paysannes/indigènes afin qu'elles puissent garder le contrôle des circuits de production et de commercialisation mais également les valeurs identitaires et symboliques liées à l'alimentation et à sa culture.

\section{Les maïs en tant que patrimoine alimentaire}

Les différences régionales des cultures de maïs s'inscrivent dans diverses stratégies générales de transformation réflexive des cycles de la nature dans le but d'obtenir des 
aliments et autres produits utiles, lesquels font partie du patrimoine bio-culturel mexicain. En outre, l'agriculteur, dans le passé, qu'il fut indigène ou métis, était également cueilleur, pêcheur et chasseur, ce qui lui donnait un savoir spécifique sur la distribution des animaux et des plantes, sur les cycles biologiques et l'utilité de cette richesse naturelle. Les maïs s'inscrivent alors dans la logique de métamorphose des milpas et des systèmes de cultures hautement bio-diversifiés (solares, conucos, pach pakales $)^{9}$, mais aussi dans la logique d'une modification diversifiée et cyclique des socioécosystèmes (forêts, bois, fleuves, systèmes côtiers, lagunes) (Hernandez-Xolocotzi 1959, Howes \& Chambers 1980, Brush 1986, Brush et al. 1988, Gadgil et al. 1993, Ramos 2003). Les multiples interactions historiques entre les sociétés et leurs natures forgèrent les diverses cultures alimentaires.

«Chacune est le produit d'une infinité de décisions tout au long de l'histoire [...] Elles contribuèrent toutes à nourrir l'identité, et elles développèrent la vie des personnes " (Camou $2008: 30-31$ ).

La culture alimentaire est l'accumulation des représentations, croyances, savoirs et pratiques hérités, appris et partagés par les individus d'une culture ou d'un groupe social donné (Casas et al. 1987, Contreras 2008, Bertran 2005, Sherwood et al. 2017). L'alimentation est liée aux valeurs et représentations socio-culturelles qui guident la consommation et donc, les aliments ne sont pas des éléments objectifs, puisqu'ils ont différentes significations selon le groupe social. Chaque culture alimentaire crée un système complexe de règles de conduite, de pratiques collectives, d'habitudes individuelles recréées dans une collectivité (Weismantel 1994). Elle va de l'approvisionnement, de la production, des systèmes de distribution, des méthodes de stockage et de conservation, et enfin de la préparation des aliments et des formes de consommation tant rituelles et symboliques que matérielles.

Conditionnées par les niches microclimatiques et les facteurs écologiques, ces interactions sociales et bio-culturelles amenèrent à la sélection de certaines variétés et races de maïs pour certains aliments et boissons, sur tout le territoire national (Figure 1), ce qui va forger les cultures alimentaires régionales constituant le patrimoine bio-culturel des Mexicains (Anderson 1947, Casas et al. 1987, Ortega-Paczka 2003, Brush \& Perales 2007, Oseguera 2008, Aragón 2010, Fernández et al. 2013).

Cependant, cette richesse alimentaire et culturelle des cuisines régionales va s'érodant. Dans toute culture, il y a des transformations à court et long terme, réversibles ou définitives, partielles ou totales et, en alimentation, de tels changements ont également lieu (Weismantel 1994, Sherwood et al. 2017). D'un côté, les sociétés rurales s'urbanisent matériellement et/ou symboliquement; d'un autre côté, les diverses cultures entrent en relation et alors, on observe des contraintes, soumissions ou des échanges culturels. Cependant, il y a parfois des pertes et parfois des gains. Malheureusement, ce qui s'est passé dans les dernières décennies au Mexique concernant la sécurité alimentaire n'a été que pertes. D'un côté, notre production nationale d'aliments de base est insuffisante, l'approvisionnement régional est très inégal, un accès à une alimentation saine est limité par manque de revenus stables et par une forte présence de l'industrie alimentaire, une baisse dans la qualité nutritionnelle et sanitaire des produits menace également le germoplasme agro-alimentaire. D'un autre côté, nous importons des aliments industrialisés de mauvaise qualité (Contreras 2008, Ortega \& Alcalá 2008, Oseguera 2008). Tout cela nous a mené à estimer que 20 millions de personnes du milieu rural, c'est-à-dire que $80 \%$ des populations rurales vivent en situation de risque 
alimentaire (Oseguera 2008 : 157, INEGI-Encuesta Nacional de Ingresos y Gastos de los Hogares, 2018).

En effet, diverses causes entraînent la modification des patrons alimentaires: la migration, le prix des maïs natifs, ${ }^{10}$ la pénétration du marketing du secteur agroalimentaire qui influe sur la culture alimentaire et substitue les aliments locaux par des industrialisés.

Pour le cas des maïs, les critères commerciaux des tortilleros, fabricants de galettes (tortillas), ont mené au remplacement des maïs natifs par des hybrides. Ceux-ci ont un meilleur rendement de la pâte par kilo de maïs. Par exemple, le Président de l'Industrie de la Pâte et de la Tortilla de Tlaxcala nous commente que les maïs hybrides de Sinaloa ont un rendement de 1,5 à 1,8 kg de pâte par kilogramme de maïs; en revanche, les maïs natifs oscillent entre 1,4 à $1,5 \mathrm{~kg}$ de pâte par kilogramme de maïs. Cependant, il reconnaît également qu'un maiis natif, connu sous le nom de arrocillo, cultivé sur les pentes de La Malinche dans le village de San José Teacalco avait un rendement égal à celui des hybrides sans utiliser d'additif et de texturisant. On ignore les raisons pour lesquelles on a cessé de cultiver ce maïs. En général, l'industrie de la tortilla préfère l'usage des maïs hybrides, parfois aussi, un mélange d'hybrides avec les natifs. Dernièrement, certaines tortillerías ont favorisé l'utilisation de maïs natifs pour vendre des produits de type " gourmet ». Ainsi, dans la région du Lac de Pátzcuaro, Michoacán, moins de $3 \%$ du maïs utilisé dans les tortillerías est récolté localement, et le maïs qui se vend dans les boutiques et qu'utilisent les tortillerías est principalement produit dans le Sinaloa et dans la Ciénega de Chapala (Orozco et al. 2010).

39 Par ailleurs, pour la confection des tlayudas dans l'État de Oaxaca, les familles n'utilisent plus exclusivement les races Bolita et Pepitilla. La rareté des maïs Bolita et Pepitilla fait qu'ils ne sont plus la source unique pour la confection des tlayudas.

«Pour chaque kilogramme de maïs criollo, c'est-à-dire indigène, utilisé dans la

fabrication de la tortilla tlayuda, on doit inclure d'un demi-kilogramme à 7

kilogrammes de maïs d'origine extérieure à la région et qui n'est pas criollo » (Ramírez $2012: 60$ ).

40 Ces exemples démontrent la perte de patrimoine alimentaire bio-culturel qui caractérise les maiis mexicains et correspond au manque de soutien de la production familiale à petite échelle. Certaines institutions sont préoccupées par ces dynamiques et essaient de souligner l'importance de la conservation des maïs natifs à travers des études à long terme (par exemple, le Projet Global des Maïs Natifs mené par Conabio).

\section{Projet global des Maïs Natifs - CONABIO}

En 2011, on présenta les résultats du " Projet Global des Maïs Natifs " ${ }^{11}$ qui rendit visible l'existence de races de maïs natifs sur tout le territoire national et a permis d'arriver à la conclusion que tout le territoire mexicain devrait être centre d'origine et de diversification (Figure 1). La base des données du projet a été construite à partir des résultats de plusieurs équipes de recherche qui ont travaillé de 2005 à 2011. Dans le total des 7950 collectes nationales, l'information socio-économique et culturelle était fortement hétérogène. La base présentait quelques rubriques complètes qui permettaient une comparaison entre les États du Mexique; il y eut aussi des parties vides d'information (notamment celles concernant les surfaces, les rendements, les caractéristiques topographiques, les types de sols). Parfois, les cultures associées au 
maïs sont très bien décrites; parfois elles ne sont qu'évoquées. Cela a généré un déséquilibre des données non seulement entre les États, mais aussi à l'intérieur d'un même État. Parfois encore, de nombreuses réponses sur les aspects socio-économiques (surfaces, rendements, densités) et écologiques (type de sols, reliefs) sont incomplètes et inutilisables pour notre analyse.

Ce manque de données rend la démonstration non statistiquement significative pour l'analyse socio-économique et culturelle, puisqu'elle ne fournit pas les règles d'un échantillonnage formel. Les surfaces de l'échantillonnage ont été choisies par chaque équipe de recherche, c'est pourquoi tous les territoires ne sont pas renseignés également et ne possèdent pas la même rigueur statistique. Cependant, nous pouvons noter quelques tendances entre les trois régions en se basant sur les cinq premières variables que nous développerons plus loin.

Considérons, enfin, que si nous ne pouvons arriver à établir de comparaisons, ni des conclusions définitives, nous pouvons cependant constituer des tendances importantes et mettre en relation diverses variables nous permettant d'affirmer que ce qui est le plus menacé est l'aspect inaliénable du patrimoine bio-culturel, en termes de savoirs et processus communautaires. Il est donc important de le prendre en compte dans le projet de la conservation du patrimoine des maïs natifs.

Malgré ces manques, le contenu de la base des données du Projet est très riche pour ce qui concerne l'information de première main et très variée sur les façons de cultiver les maïs natifs. En outre, elle nous donne, pour la première fois, dans le domaine de la recherche sur les maïs, de manière désagréguée, des données très variées pour chaque race de maïs cultivée. Il s'agit de comprendre la valeur et le sens que les maïs donnent encore à la vie des agriculteurs de notre pays. L'analyse sociale et bio-culturelle des collectes de maïs natifs réaffirme leur rôle primordial dans la culture paysanne de quelques régions et livre des éléments pour constater l'importance de les entretenir dans toute leur diversité bio-culturelle.

\section{Comparaison des maïs natifs entre le nord, le centre et le sud du pays}

45 La valeur des maïs natifs liée à la culture alimentaire mais également à l'identité et à son importance en tant que ressource aliénable et inaliénable a été analysée. Toutefois, la biodiversité de ces maïs, qui sont localisés sur l'ensemble du territoire et qui caractérise ainsi le fait d'être centre d'origine et de diversification du maïs, ne fait en aucune manière référence à un univers homogène. Bien au contraire, les processus bioculturels apportent un savoir localisé, il est donc important de comparer les conditions dans lesquelles sont produits les maïs natifs des trois régions du pays. Cela nous a permis de découvrir de nouvelles réalités et de les confronter aux politiques publiques qui ont été mises en place à ce sujet.

Pour comparer la richesse, la conservation et la production de maïs natifs entre les trois régions, Nord, Centre et Sud, nous avons choisi les variables suivantes à partir de la base de données des 7950 collectes réunies par CONABIO : a) diversité des maïs, b) association de maïs, c) cultures associées, d) but de la production, e) surface cultivée, f) accès à l'irrigation, usage de fertilisants et engrais organiques. Bien que toutes ces variables soient liées entre elles, nous les avons analysées séparément pour faire 
ressortir et expliquer les similitudes et les différences qui existent entre les trois régions. Les quatre premières variables concernent les pratiques agricoles qui contribuent à donner valeur et sens aux maïs et les trois autres sont spécifiques à la gestion des cultures en fonction des conditions existantes dans chaque région.

Les facteurs qui expliquent les grandes inégalités agricoles régionales sont multiples: les conditions écologiques, les dynamiques économiques, sociales et démographiques, les identités culturelles. Ces différences sont souvent des clichés. Par exemple, au nord du pays où prévalent des pôles agro-industrialisés, avec un climat aride et semi-aride, les races de maïs natifs seraient peu présentes et même inexistantes. En revanche, au sud où prédominent les populations indigènes, on trouve un plus grand nombre vivant sous le système de la milpa pour l'autoconsommation. Cependant, bien que les politiques de développement aient provoqué ces différences, nous observons des contrastes puisqu'au nord comme au centre et au sud, il existe une diversité de mosaïques écologiques, culturelles, socio-économiques et politiques qui poussent les populations rurales, métisses et indigènes à cultiver une très grande richesse de maïs natifs. Cette comparaison entre la diversité des maïs, leur gestion et la production des diverses races de maïs au nord, centre et sud, permet de mettre en évidence, avec les données actuelles, les conditions de vulnérabilité dans laquelle se maintiennent autant l'agriculture traditionnelle de la milpa que le savoir de cette richesse bio-culturelle.

C'est le concept du maïs, comme capital naturel ou comme commodity, qui, devant la pression des entreprises transnationales, pour faire adopter le maïs transgénique, a poussé le ministère de l'agriculture (SAGARPA) à proposer la division du pays. Le nord, comme étant le grand producteur de maïs commercial, pourrait être l'objet de l'expérimentation des maïs transgéniques, puisque on part de la supposition qu'il est presque dépourvu de populations de maïs natifs. Alors que le sud, grand producteur de diversité de maïs, pourrait être la région destinée à la conservation du matériel génétique du maïs natif. Cette perception réductionniste, qui fait de la localisation et de l'importance des races de maïs natif dans le pays, est invalidée par les résultats du Projet global, puisque celui-ci rend évident l'existence de races de maïs sur tout le territoire national, lorsqu'il a actualisé les travaux précédents en la matière et qu'il a souligné l'importance des maïs natifs dans l'alimentation des populations rurales de tout le pays.

\section{Diversité des maïs natifs au nord, centre et sud du pays ${ }^{12}$}

49 Au nord, des 1933 collectes, on a enregistré 32 races de maïs. Les races les plus largement distribuées sont la Cónico Norteño, Tuxpeño, Tabloncillo, Ratón et Tuxpeño Norteño, lesquelles représentent $70 \%$ des collectes ${ }^{13}$. Alors que les races les moins distribuées ou bien qui furent peut-être collectées en moindre quantité ou encore qui purent présenter une tendance à l'érosion génétique ${ }^{14}$ sont: Dzit Bacal, Elotes Cónicos, Mushito, Palomero de Chihuahua, Harinoso de Ocho et Cacahuacintle, lesquelles représentent moins de $1 \%$ des collectes (Tableau 1 ). 
Tableau 1 : Nord : Diversité de races collectées

\begin{tabular}{|c|c|c|c|c|c|}
\hline Race & Pourcentage & Race & Pourcentage & Race & Pourcentage \\
\hline Apachito & $2.22 \%$ & Elotero de Sinaloa & $1.81 \%$ & Tablilla de Ocho & $0.47 \%$ \\
\hline Azul & $3.78 \%$ & Elotes Cónicos & $0.10 \%$ & Tabloncillo & $12.98 \%$ \\
\hline Blando & $0.78 \%$ & Elotes Occidentales & $0.83 \%$ & Tabloncillo Perla & $0.83 \%$ \\
\hline Bofo & $0.41 \%$ & Gordo & $2.48 \%$ & Tuxpeño & $17.64 \%$ \\
\hline Bolita & $0.67 \%$ & Harinoso de Ocho & $0.05 \%$ & Tuxpeño Norteño & $7.24 \%$ \\
\hline Cacahuacintle & $0.05 \%$ & Jala & $0.36 \%$ & Vandeño & $1.03 \%$ \\
\hline Celaya & $4.50 \%$ & Mushito & $0.10 \%$ & ND & $0.72 \%$ \\
\hline Chapalote & $0.52 \%$ & Olotillo & $0.72 \%$ & & \\
\hline Cónico & $0.57 \%$ & Onaveño & $0.78 \%$ & & \\
\hline Cónico Norteño & $19.97 \%$ & Palomero de Chihuahua & $0.10 \%$ & & \\
\hline Cristalino de Chihuahua & $5.12 \%$ & Pepitilla & $0.26 \%$ & & \\
\hline Dulcillo del Noroeste & $0.16 \%$ & Ratón & $12.05 \%$ & & \\
\hline Dzit Bacal & $0.10 \%$ & Reventador & $0.57 \%$ & & \\
\hline
\end{tabular}

Source : Elaboration personnelle basée sur CONABIO 2010

$\mathrm{Au}$ centre, on a enregistré 35 races de maïs ; les races les mieux distribuées sont Cónico, Elotes Cónicos, Tuxpeño, Olotillo et Elotes Occidentales, lesquelles correspondent à $48 \%$ des 2904 collectes. Les races à distribution restreinte ou qui auront été probablement collectées en plus petite quantité ou qui même, peuvent présenter une tendance à l'érosion génétique sont: Mountain Yellow, Tuxpeño Norteño, Complejo Serrano de Jalisco, Negrito, Tablilla de Ocho et Cubano Amarillo, lesquelles sont moins de $1 \%$ des collectes totales. (Tableau 2).

51 Au sud on a enregistré 32 races de maïs (Tableau 3). Les races les plus importantes sont Tuxpeño, Olotillo et Tepecintle, lesquelles représentent $52 \%$ des 3113 collectes. Les races à distribution restreinte ou dont la collecte fut restreinte ou qui sont peut-être en voie d'érosion sont: Onaveño, Zapalote Chico et Cacahuacintle, lesquelles représentent moins de $1 \%$ des collectes. Cependant, dans l'État de Oaxaca, la production du Zapalote Chico est en hausse à cause du boom du totopos, typiquement réalisés avec cette race et qui est d'ailleurs exportée vers les États-Unis. Les proportions du Tuxpeño Norteño ont enregistré une baisse dans le sud, mais, dans le nord, il s'agit d'une des races les plus largement distribuées. En définitive, il existe un va-et-vient entre les diminutions et les augmentations de population de races, dépendant des facteurs écologiques, alimentaires et commerciaux. 
Tableau 2 : Centre : Diversité de races collectées

\begin{tabular}{|c|c|c|c|c|c|}
\hline Race & Nombre & Pourcentage & Race & Nombre & Pourcentage \\
\hline Ancho & 193 & $6.65 \%$ & Mushito de Michoacán & 54 & $1.86 \%$ \\
\hline Arrocillo Amarillo & 65 & $2.24 \%$ & Negrito & 2 & $0.07 \%$ \\
\hline Bolita & 38 & $1.31 \%$ & Olotillo & 229 & $7.89 \%$ \\
\hline Cacahuacintle & 30 & $1.03 \%$ & Olotón & 11 & $0.38 \%$ \\
\hline Celaya & 151 & $5.20 \%$ & Onaveño & 20 & $0.69 \%$ \\
\hline Complejo Serrano de Jalisco & 2 & $0.07 \%$ & Palomero Toluqueño & 5 & $0.17 \%$ \\
\hline Conejo & 27 & $0.93 \%$ & Pepitilla & 65 & $2.24 \%$ \\
\hline Cónico & 452 & $15.56 \%$ & Ratón & 30 & $1.03 \%$ \\
\hline Cónico Norteño & 133 & $4.58 \%$ & Reventador & 28 & $0.96 \%$ \\
\hline Coscomatepec & 5 & $0.17 \%$ & Tabloncillo & 63 & $2.17 \%$ \\
\hline Cubano Amarillo & 1 & $0.03 \%$ & Tablilla de Ocho & 2 & $0.07 \%$ \\
\hline Chalqueño & 172 & $5.92 \%$ & Tabloncillo Perla & 20 & $0.69 \%$ \\
\hline Dulce & 16 & $0.55 \%$ & Tepecintle & 19 & $0.65 \%$ \\
\hline Elotes Cónicos & 256 & $8.82 \%$ & Tuxpeño & 236 & $8.13 \%$ \\
\hline Elotero de Sinaloa & 36 & $1.24 \%$ & Tuxpeño Norteño & 3 & $0.10 \%$ \\
\hline Elotes Occidentales & 203 & $6.99 \%$ & Vandeño & 93 & $3.20 \%$ \\
\hline Mountain Yellow & 3 & $0.10 \%$ & Zamorano Amarillo & 33 & $1.14 \%$ \\
\hline Mushito & 10 & $0.34 \%$ & ND & 198 & $6.82 \%$ \\
\hline
\end{tabular}

Source : Elaboration personnelle basée sur CONABIO 2010

Tableau 3 : Sud : Diversité de races collectées

\begin{tabular}{l|c|c||c|c|c|}
\multicolumn{1}{c|}{ Race } & Nombre & Pourcentage & \multicolumn{1}{c|}{ Race } & Nombre & Pourcentage \\
\hline Ancho & 48 & $1.54 \%$ & Olotillo & 493 & $15.84 \%$ \\
\hline Arrocillo Amarillo & 29 & $0.93 \%$ & Olotón & 8 & $0.26 \%$ \\
\hline Bolita & 9 & $0.29 \%$ & Onaveño & 2 & $0.06 \%$ \\
\hline Cacahuacintle & 1 & $0.03 \%$ & Palomero Toluqueño & 6 & $0.19 \%$ \\
\hline Celaya & 22 & $0.71 \%$ & Pepitilla & 87 & $2.79 \%$ \\
\hline Comiteco & 61 & $1.96 \%$ & Ratón & 51 & $1.64 \%$ \\
\hline Conejo & 39 & $1.25 \%$ & Serrano & 8 & $0.26 \%$ \\
\hline Cónico & 37 & $1.19 \%$ & Tabloncillo & 5 & $0.16 \%$ \\
\hline Coscomatepec & 37 & $1.19 \%$ & Tehua & 16 & $0.51 \%$ \\
\hline Chalqueño & 5 & $0.16 \%$ & Tepecintle & 288 & $9.25 \%$ \\
\hline Dzit Bacal & 32 & $1.03 \%$ & Tuxpeño & 908 & $29.17 \%$ \\
\hline Elotes Cónicos & 38 & $1.22 \%$ & Tuxpeño Norteño & 5 & $0.16 \%$ \\
\hline Elotes Occidentales & 91 & $2.92 \%$ & Vandeño & 98 & $3.15 \%$ \\
\hline Mountain Yellow & 1 & $0.03 \%$ & Zapalote Chico & 2 & $0.06 \%$ \\
\hline Mushito & 42 & $1.35 \%$ & Zapalote Grande & 28 & $0.90 \%$ \\
\hline Nal-tel & 35 & $1.12 \%$ & ND & 573 & $18.41 \%$
\end{tabular}

Source : Elaboration personnelle basée sur CONABIO 2010

52 Ensuite, viennent les races qui sont présentes dans plus d'une région ou que l'on trouve même dans les trois régions. Le centre et le nord partagent 22 races, alors que le sud a en commun 24 races avec le centre et 20 races avec le nord (Tableau 4). 16 races sont présentes dans les trois territoires. [Insérer le tableau 4] 
Tableau 4 : Nord, Centre et Sud : Comparaison des races collectées

\begin{tabular}{|c|c|c|c|c|c|c|c|c|c|c|c|}
\hline Race & N & C & s & Race & N & C & S & Race & N & C & S \\
\hline Ancho & & 1 & 1 & Dulcillo del Noroeste & 1 & & & Palomero Toluqueño & & 1 & 1 \\
\hline Apachito & 1 & & & Dulce & & 1 & & Pepitilla & 1 & 1 & 1 \\
\hline Arrocillo Amarillo & & 1 & 1 & Dzit Bacal & 1 & & 1 & Ratón & 1 & 1 & 1 \\
\hline Azul & 1 & & & Elotero de Sinaloa & 1 & 1 & & Reventador & 1 & 1 & \\
\hline Blando & 1 & & & Elotes Cónicos & 1 & 1 & 1 & Serrano & & & 1 \\
\hline Bofo & 1 & & & Elotes Occidentales & 1 & 1 & 1 & Tablilla de Ocho & 1 & 1 & \\
\hline Bolita & 1 & 1 & 1 & Gordo & 1 & & & Tabloncillo & 1 & 1 & 1 \\
\hline Cacahuacintle & 1 & 1 & 1 & Harinoso de Ocho & 1 & & & Tabloncillo Perla & 1 & 1 & \\
\hline Celaya & 1 & 1 & 1 & Jala & 1 & & & Tehua & & & 1 \\
\hline Comiteco & & & 1 & Mountain Yellow & & 1 & 1 & Tepecintle & & 1 & 1 \\
\hline Complejo Serrano de Jalisco & & 1 & & Mushito & 1 & 1 & 1 & Tuxpeño & 1 & 1 & 1 \\
\hline Conejo & & 1 & 1 & Mushito de Michoacán & & 1 & & Tuxpeño Norteño & 1 & 1 & 1 \\
\hline Cónico & 1 & 1 & 1 & Nal-tel & & & 1 & Vandeño & 1 & 1 & 1 \\
\hline Cónico Norteño & 1 & 1 & & Nal-tel de Altura & & & 1 & Zamorano Amarillo & & 1 & \\
\hline Coscomatepec & & 1 & 1 & Negrito & & 1 & & Zapalote Chico & & & 1 \\
\hline Cristalino de Chihuahua & 1 & & & Olotillo & 1 & 1 & 1 & Zapalote Grande & & & 1 \\
\hline Cubano Amarillo & & 1 & & Olotón & & 1 & 1 & ND & 1 & 1 & 1 \\
\hline Chalqueño & & 1 & 1 & Onaveño & 1 & 1 & 1 & & & & \\
\hline Chapalote & 1 & & & Palomero de Chinuahua & 1 & & & & & & \\
\hline
\end{tabular}

1 : marque la présence ; $N=$ nord, $C=$ centre, $S=$ sud

Source : Elaboration personnelle basée sur CONABIO 2010

53 Cette diversité, peut-on dire, répond à l'aspect inaliénable comme patrimoine bioculturel; elle correspond également aux savoirs appliqués à chaque race et leurs multiples relations avec les autres races, les sols, la sécheresse, la résistance aux maladies, entre autres. "Les producteurs cultivent leurs variétés en se basant sur les nombreuses caractéristiques: climatiques (résistance aux divers problèmes météorologiques), agronomiques (adaptation au type de sol), biologiques (résistance aux maladies et aux mauvaises herbes), et socio-culturelles (la saveur, les qualités et caractéristiques lors de la préparation de divers petits plats » (Lazos \& Chauvet 2012 : 7).

\section{Association des maïs natifs}

Quant aux maïs associés sur une même parcelle, au nord on attendrait une majorité de monoculture (une seule race de maïs). Cependant, l'association de plusieurs races de maïs sur une même parcelle est semblable au nord et au sud. Par le passé, alors que $55 \%$ des producteurs du nord semaient plusieurs races de maïs sur leurs parcelles; 59 \% des producteurs du sud faisaient de même. Par contraste, moins de la moitié (36 \%) des producteurs du centre cultivaient plusieurs races sur leurs parcelles, ce qui peut être dû à l'influence de l'industrie de la tortilla qui préfère le maïs d'une seule race (Figure 2). 
Figure 2 : Association des maïs natifs

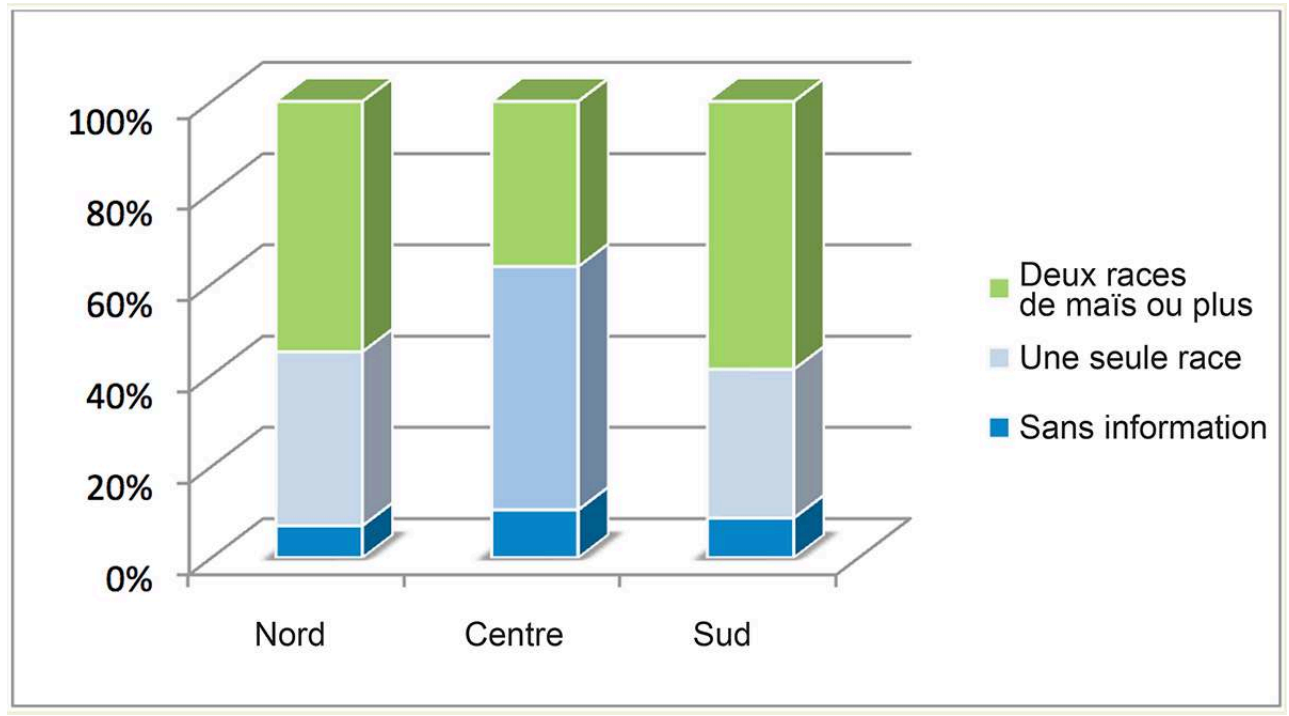

Source : Elaboration personnelle basée sur CONABIO 2010

Cette diversité de races est liée à la culture alimentaire traditionnelle. Certains maïs servent principalement à la fabrication de certains produits ou plats spécifiques, ce qui évoque des valeurs, des saveurs, des styles et des assaisonnements locaux. Autour de ces différences de terroirs, se créent les cuisines régionales. Quelques produits ou cultures particulières forment une part fondamentale de la culture alimentaire régionale et leur conservation pourrait stimuler d'autres versants de la vie matérielle et symbolique du lieu. Ainsi, au Sinaloa, avec le maïs Blando on fabrique des galettes très populaires : coricos ou tacuarin (elles sont rondes) ou pinturitas (petites et servies dans les mariages). Le maïs «Jasmin du Sud», nom commun du Tabloncillo, est une race largement distribuée dans l'État du Sinaloa (Palacios et al., 2008), c'est le préféré pour les tortillas et la boisson connue sous le nom tesgüino, très consommée chez les Raramuri ${ }^{15}$, et aussi dans les États de Sinaloa et Jalisco. A Jala, Nayarit, le 15 août a lieu la grande fête patronale de l'Assomption, dont la principale attraction sont les savoureux elotes ${ }^{16}$ de maïs Jala dont les épis sont plus grands que les maïs normaux, ils peuvent dépasser 40 centimètres (González 2009). On pourrait donner de très nombreux exemples de maïs natifs avec lesquels on élabore de plats spécifiques dans toutes les régions (Fernández et al. 2013) même s'ils ne sont pas toujours faits de cette manière puisque la population de certains maïs natifs ne couvre pas la demande alimentaire. C'est notamment le cas des tlayudas qui à l'origine étaient élaborées avec du maïs Bolita, mais actuellement, les tortilleras sont obligés d'utiliser des maïs hybrides venant de l'État du Sinaloa.

\section{Les cultures associées au maïs}

Concernant les cultures associées au maïs, la tendance est la monoculture (basé sur $67 \%$ des questionnaires réalisés avec 4683 producteurs des 7009 totaux). Cependant, à partir des données de la base, on constate des différences régionales. Dans le nord, la plus grande partie des producteurs cultivent en monoculture (87\%, c'est-à-dire 1314 des 1510 enquêtés); au sud, la moitié des producteurs cultivent en culture associée (53\%, c'est-à-dire 1578 des 2993 producteurs). Le centre montre une tendance 
semblable à celle du nord, bien qu'avec un pourcentage moindre de monoculture (78 \%, 1954 de 2506 producteurs) (Figure 3).

Figure 3 : Régions : association des cultures et maïs natifs

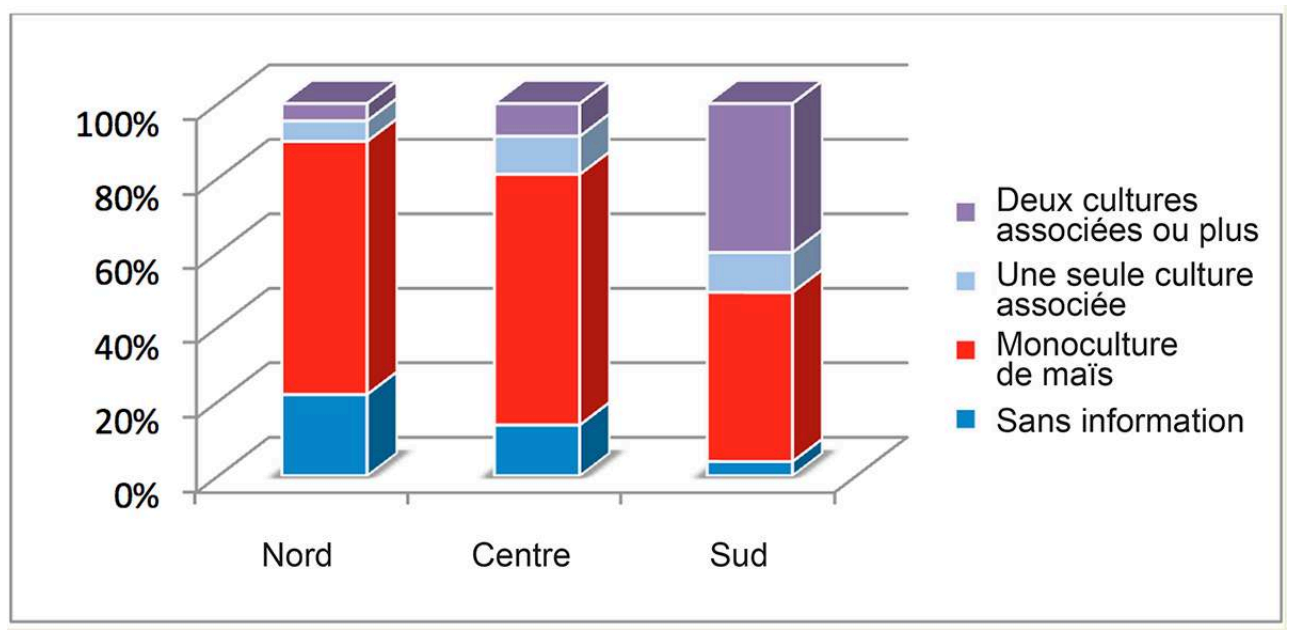

Source : Elaboration personnelle basée sur CONABIO 2010

57 L'abandon progressif, au nord et au centre du pays, de la culture milpera qui consiste à associer diverses cultures, obéit principalement à deux causes: 1) l'adoption de pratiques agricoles industrielles qui, introduisant des herbicides, empêchent la coexistence d'autres cultures sur la parcelle et 2) le manque de main d'œuvre dû à la migration ou à l'emploi dans d'autres activités comme l'agriculture commerciale d'exportation ou les industries au nord. Tout cela a amené à la perte des savoirs sur les diverses associations de plantes et rotation des cultures qui contribuent à récupérer la fertilité des sols.

\section{Le but de la production}

Le but de la production des maïs natifs est d'abord l'autoconsommation, c'est ce qu'ont répondu $58 \%$ du total des producteurs enquêtés ${ }^{17}$. Le tiers $(30 \%)$ combine l'autoconsommation avec la vente au marché et moins de $5 \%$ destine la production pour la seule vente. Les différences régionales sont claires : $72 \%$ des producteurs du sud destinent leur production à l'autoconsommation; c'est le cas d'un peu plus de la moitié des producteurs au centre (56\%). Cependant, le nord présente aussi une forte proportion de producteurs (59\%) qui destinent principalement leur maïs à l'autoconsommation (Figure 4). Ainsi nous pouvons affirmer que l'autoconsommation n'est pas seulement revendiquée par les régions du sud. 
Figure 4 : Débouchés de la production

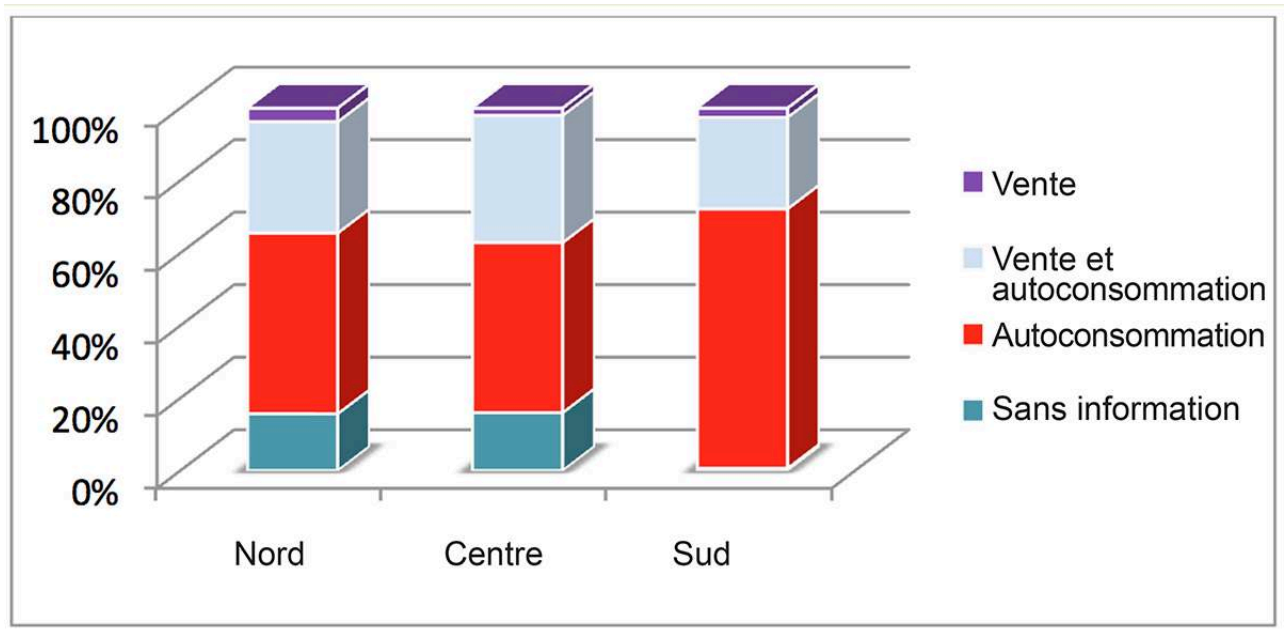

Source : Elaboration personnelle basée sur CONABIO 2010

\section{Surfaces cultivées de maïs natifs}

En général, las surfaces cultivées sont de petite taille (Figure 5). Selon les données, la moitié des producteurs ( $48.5 \%$, soit 811 sur 1669 producteurs enquêtés sur le sujet) cultive moins de deux hectares et $42 \%$ (701 sur 1669) entre deux et cinq hectares. Seuls $9 \%$ (157 des 1669) cultive plus de cinq hectares. Il n'a pas été possible d'obtenir une analyse régionale complète, puisque les équipes enquêtant au centre n'ont presque pas tenu compte de cette information et par conséquent, cette région n'a pas été prise en compte dans cette analyse. Les tendances qui se dessinent, à partir des questionnaires avec données, au nord et au sud, révèlent qu'au sud presque tous les enquêtés (99\%) cultivent des surfaces de moins de cinq hectares et la majeure partie de ceux-ci (60\%, soit 546 des 902 enquêtés $\left.{ }^{18}\right)$ cultivent des surfaces de moins de deux hectares. Au nord, $20 \%$ des producteurs (soit 130 des 603 enquêtés) plantent des maïs natifs sur des surfaces de plus de cinq hectares. En d'autres termes, au sud, la majorité des parcelles ont moins de cinq hectares; alors que les parcelles de plus de cinq hectares se trouvent majoritairement au nord (Figure 6). 
Figure 5 : Superficie cultivée avec des maïs natifs

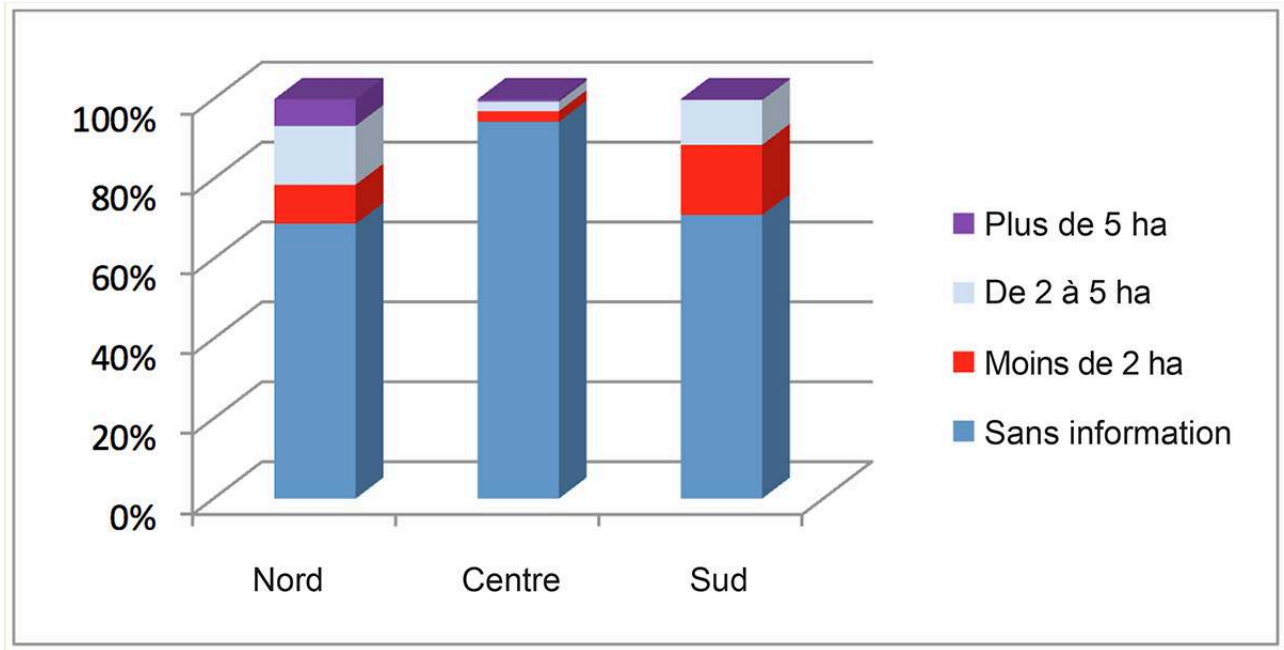

Source : Elaboration personnelle basée sur CONABIO 2010

Figure 6 : Distribution de la surface cultivée par région

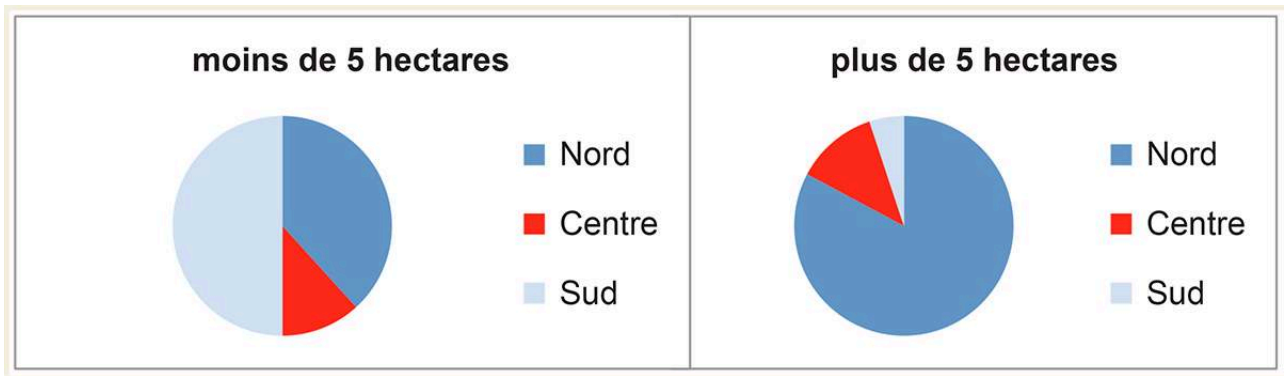

Source : Élaboration personnelle basée sur CONABIO 2010

La plupart des données de l'enquête montre que les surfaces cultivées en maïs natifs sont des minifundistes. Depuis plusieurs décennies, le minifundisme ${ }^{19} \mathrm{a}$ été considéré comme étant une fragmentation de l'économie paysanne et effectivement la taille des parcelles dans le groupe des deux à cinq hectares n'est pas l'optimum pour faire vivre une famille, cependant, il est surprenant de constater que, malgré une rentabilité basse, $40 \%$ de la production agricole nationale vient des dites parcelles et en outre ce secteur agricole est celui qui génère le plus d'emploi rural (Robles 2016).

\section{Les technologies utilisées : irrigation, fertilisants, engrais verts}

61 La majeure partie des parcelles ( $73 \%$, soit 5782 des 7950 producteurs) dépendent des pluies. Au sud, on n'irrigue presque pas les maïs natifs. La plupart des parcelles irriguées se trouvent au nord ( $19 \%$, soit 348 des 1850 producteurs) et au centre ( $27 \%$, soit 724 des 2679 producteurs). Pour $10 \%$ des parcelles on utilise un autre accès à l'eau, par exemple l'humidité résiduelle (Figure 7). 
Figure 7 : Parcelles avec accès à une source d'eau

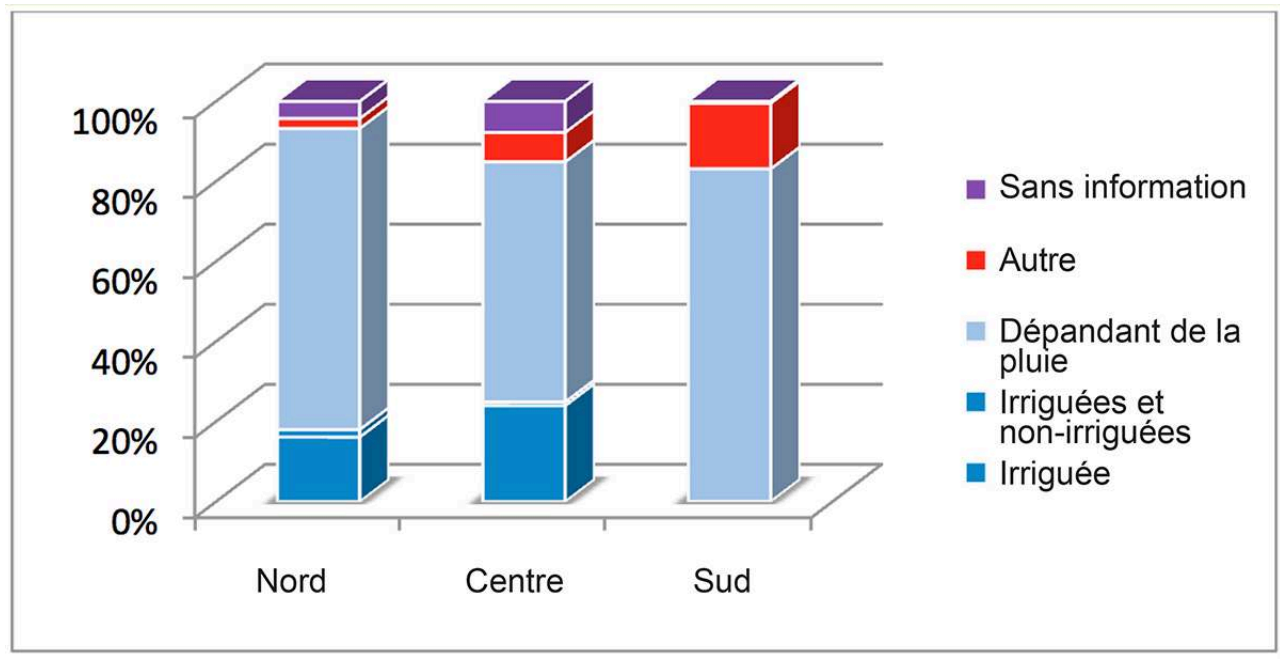

Source : Élaboration personnelle basée sur CONABIO 2010

Il est surprenant que $32 \%$ des producteurs totaux n'utilisent ni engrais ni fertilisant. La moitié des producteurs (53\%) font appel aux fertilisants chimiques, alors que seulement $12 \%$ utilise des engrais organiques et $3 \%$ les utilise en mélange. Au nord, prédominent les producteurs n'utilisant aucun type de fertilisant $(58,4 \%)$, alors qu'au sud prévalent les producteurs qui appliquent des fertilisants chimiques (65\%). Le centre est dans une situation intermédiaire. (Figure 8).

Figure 8 : Utilisation d'engrais et fertilisants

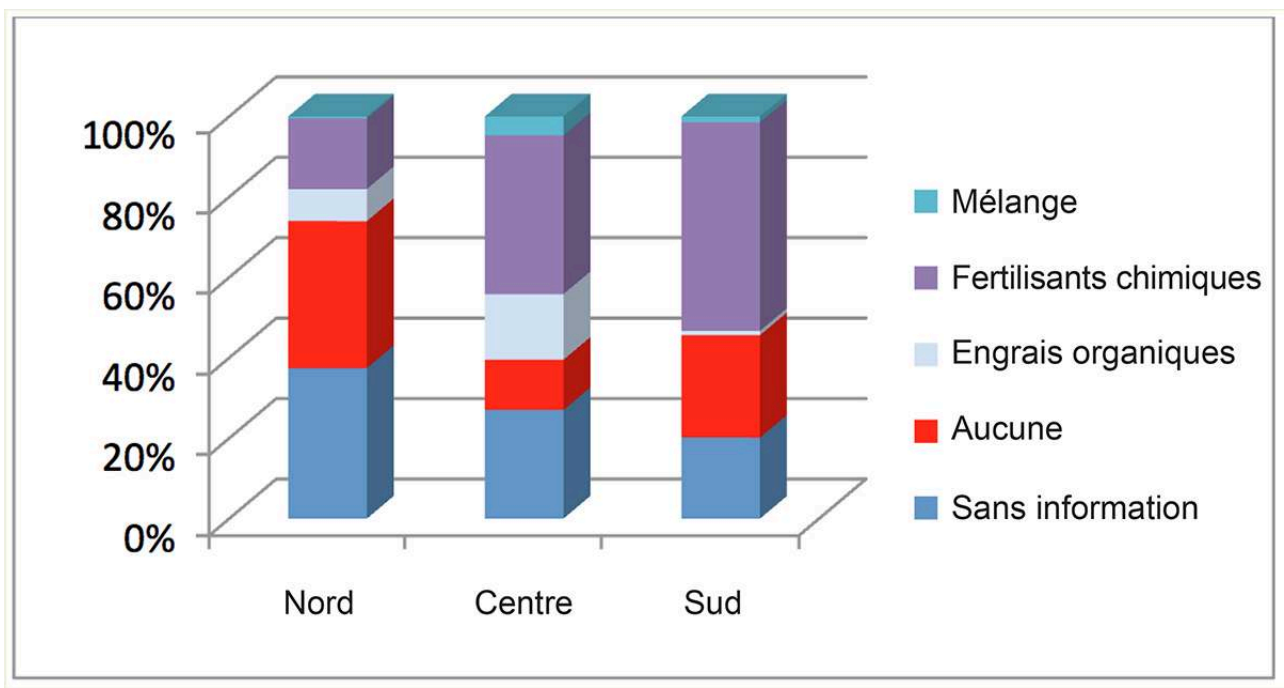

Source : Élaboration personnelle basée sur CONABIO 2010

Cette variable rend évidente l'influence du modèle agro-industriel, qui provoque une très forte dégradation écologique surtout au sud du pays; cela a eu un effet sur les savoirs traditionnels: appauvrissement des connaissances concernant les cultures associées, et la rotation des cultures. En outre, la migration croissante a provoqué non seulement l'abandon de certaines cultures, mais aussi des savoirs associés à ces cultures et en conséquence la perte du patrimoine bio-culturel et communautaire. En effet, l'une des conséquences de la migration a été la transformation du tissu social qui coïncide 
également avec le vieillissement de la population rural (Mestries 2002). Selon l'enquête nationale agricole de 2017, 38,6\% des producteurs ont plus de 60 ans (ENA 2017). Ces deux phénomènes ont contribué á la disparition des savoirs sur les propriétés de plusieurs types de maïs et risque de détruire ce patrimoine intangible construit depuis des générations.

Remarquons que l'agriculture commerciale pratiquée dans la région du nord utilise habituellement des fertilisants pour les maïs hybrides, et l'on pourrait penser que ces pratiques se transmettent aux producteurs de maïs natifs, mais c'est dans le sud que prédomine cet usage. En effet, les pratiques agricoles traditionnelles au sud ont décliné à cause de la forte émigration, le manque de main d'œuvre et la perte naturelle de la fertilité des sols par surexploitation ou la rupture du cycle forêt-milpa. Les agriculteurs ne peuvent plus mettre en jachère ces petites surfaces comme auparavant.

Une autre conséquence de l'usage de l'agrochimie, surtout des engrais chimiques, est le changement des sols pour l'élevage, celui-ci occupe de vastes surfaces qui déplace la culture du maïs vers les terres en pentes marquée par une forte érosion des sols. Lorsque l'économie familiale le permet et que se profile une bonne saison de pluie, pour récupérer la fertilité de leurs terres, les petits agriculteurs utilisent les produits chimiques. De plus, ceux-ci ont été l'objet de relations clientélaires dans le cadre de la politique nationale créant une dépendance liée à leur utilisation. "je te donne du fertilisant en échange de ton vote » a été une politique largement utilisée par les divers partis politiques.

66 L'analyse des données démontre la grande richesse des maïs natifs dans les régions étudiées, pratiquement en nombre égal. L'ensemble du territoire national, à l'exception des zones désertiques, est propice à la culture des maïs natifs. Cependant, une tendence se profile : le sistème milpa est progressivement abandonné et la mono-culture devient prédominante ce qui implique une plus grande détérioration écologique.

Cette comparaison entre les régions de culture de maïs rend patent le risque que le patrimoine inaliénable soit de plus en plus menacé entraînant sa complète transformation. L'aspect intangible et inaliénable concerne la connaissance que les agriculteurs ont de leurs maïs, et la reconnaissance de leurs qualités; eux savent quelles variétés produisent plus que d'autres; quelles sont les plus vulnérables aux maladies ou résistantes à la sécheresse ou à certains fléaux. «Les semences ont de multiples qualités qui ont été construites collectivement grâce aux relations qui vont au-delà de la délimitation de sa propriété et qui aident à constituer la valeur des semences »(Silva 2017 : 292).

Quant aux politiques publiques, l'approche prédominante est de restreindre le maïs à l'aspect aliénable, compris comme une marchandise commerciale, comme s'il s'agissait exclusivement d'une matière première de plus. L'introduction du maïs hybride est une tentative de moderniser l'agriculture, mais son application limitée n'a pas permis d'atteindre ce but (Fenzi 2017). Le programme « kilo par kilo » chercha à supplanter le maïs indigène par l'hybride, d'ailleurs sans beaucoup de succès pour deux raisons : le maïs hybride ne s'adapte pas à certaines régions; et dans certains lieux lorsque le programme fut suspendu, l'agriculteur s'est retrouvé sans semences et sans l'argent nécessaire pour acheter la semence certifiée, parce que dans la pratique on n'échange pas une graine pour une autre, mais on subventionne l'achat de maïs hybrides. L'échec de ce programme a déclenché le mécontentement et la fureur des agriculteurs qui s'est manifesté par l'assaut des bureaux de SAGARPA dans plusieurs régions. Ce programme 
est un bon exemple des politiques agricoles mises en place à partir des années 80 , privilégiant une perspective productiviste basée sur l'augmentation des rendements.

De notre point de vue, la politique agricole proposée devrait reposer sur la promotion de semis de maïs natifs en utilisant la logique de la milpa diversifiée, celle-ci pourrait s'appuyer sur l'organisation communautaire et les savoirs associés permettant aux agriculteurs d'atteindre une sécurité alimentaire locale.

\section{Conclusions}

70 La richesse de la diversité des maïs résulte de multiples processus socio-économiques, politiques, culturels et écologiques qui s'entrevoient à différents niveaux, fonctionnant parfois entre eux de manière contradictoire et dans d'autres cas, de manière complémentaire. Et malgré la migration et la semi-prolétarisation massive des paysans, la fluctuation des prix qui ne payent pas les coûts de production du maïs, la politique anti-paysanne au niveau national et la détérioration des institutions coopératives des systèmes locaux, malgré tout cela, il existe 64 races de maïs et plus de 300 variétés sur le territoire mexicain. Les petits producteurs continuent à calculer les risques et les bénéfices socio-culturels des maïs natifs comme biens aliénables qui circulent entre les familles et les communautés pour former une partie de leur alimentation. Lors des mauvaises années, même s'ils ont de bas rendements, la production couvre une partie de l'alimentation familiale. Alors que lorsqu'il s'agit de bonnes années, la production permet de récupérer le travail investi, et même de proposer du travail face aux quelques alternatives offertes localement, d'augmenter l'élevage d'animaux considérés comme des «banques vivantes » et même de pouvoir acheter des animaux et/ou de la terre. Face aux conditions écologiques adverses (érosion des sols, précipitations erratiques, événements météorologiques extrêmes), les familles paysannes continuent à préférer le maïs à d'autres cultures quand ils n'ont ni le capital suffisant pour une conversion, ni les connaissances agroécologiques ou économiques pour s'aventurer vers d'autres cultures.

71 La diversité des maïs au nord (32 races), au sud (32 races) et au centre (34 races) est très semblable; en outre, les trois régions partagent un grand nombre de races communes. Le centre et le nord en partagent 22, le nord, le centre et le sud, 24, et le nord et le sud, 20. Seize races sont cultivées sur tout le territoire du pays. Ces résultats trouvés dans les collectes renforcent la conclusion que tout le territoire mexicain est centre d'origine et de diversification du maïs.

Cette diversité des maïs a forgé peu à peu, par des processus aliénables et inaliénables, le patrimoine bio-culturel des familles paysannes. Cependant, autant par la diversité des maïs au niveau communautaire, que par les processus inaliénables qui la soutiennent, les producteurs affrontent de multiples risques: a) petites propriétés et rareté des terres; b) baisse des rendements due à la perte de fertilité des sols et à l'incapacité de la restaurer; c) risque de maladies, surtout dans l'engrangement; d) risques de perte des récoltes par les vents, le gel, la sécheresse ou d'autres événements météorologiques; e) changements de goûts culturels, incluant les culinaires; f) réduction de l'élevage d'animaux domestiques; g) cours aléatoires du marché des prix et des exigences; $h$ ) politiques anti-paysannes dues à l'absence de politiques agricoles qui soutiennent la petite production; i) érosion du tissu social puis disparition des institutions collectives locales et finalement; $j$ ) violence du crime organisé dans le 
milieu rural. Ces menaces se traduisent par une forte migration rurale, laissant la campagne vieillir et/ou se féminiser, et dans un milieu rural hautement vulnérable où les producteurs, chaque fois avec une plus grande intensité, se voient obligés de louer, abandonner ou vendre leurs parcelles.

Pour maintenir cette diversité des maïs, il faut affronter de grands défis sociaux, politiques, économiques, écologiques et culturels. S'il est certain que nous rencontrons toujours 64 races de maïs sur tout le territoire, nous ne devrons pas ignorer l'évolution des surfaces totales et les rendements et la vulnérabilité des caractéristiques écologiques de chaque race. Nous ne pouvons donc pas savoir avec certitude s'il y a eu une tendance à l'érosion génétique ou si seulement quelques races ont une distribution restreinte/localisée ou simplement si elles sont mal représentées dans les collectes nationales ou alors si nous sommes en présence des trois processus (Dyer et al. 2014). Nous rencontrons toujours différentes proportions de maïs natifs, parfois mêlés aux hybrides ou à des variétés améliorées, car leur culture dépend autant des politiques agricoles nationales que des conditions socio-économiques, écologiques et culturelles locales. Et donc, s'il est certain qu'une race ou espèce associée au maïs peut se maintenir, nous devrions vérifier si les connaissances qui l'entourent se maintiennent et si on reproduit les symboles et les savoirs de sa culture dans le vie familiale et communautaire. Par exemple, on continue à cultiver le maïs Jala, mais seuls quelques producteurs maintiennent les savoirs de sa culture.

En ce sens, la partie inaliénable du patrimoine bio-culturel des maïs natifs (connaissances, symboles, signifiants, réciprocités, sens communautaire) est hautement vulnérable. D'une part, dans de nombreuses communautés, on continue à forger des liens identitaires par la transmission de symboles, signifiants et savoirs de la culture milpera; mais dans beaucoup d'autres, les réseaux de la patrimonialisation communautaire des maïs se sont "embrouillés» ou cassés entre les familles agricultrices. Surtout chez les jeunes, les maïs natifs ne jouent plus un rôle symbolique et signifiant pour la reproduction de leur propre culture. En ce sens, pour les jeunes et dans beaucoup de communautés, les maïs ne sont plus le patrimoine bio-culturel, sinon le capital naturel. Les agriculteurs, actuellement, ne considèrent que les prix, investissements, circuits de marché et la potentialité agro-commerciale des maïs par rapport à d'autres cultures ou même, à d'autres activités (agro-tourisme, services dans les communautés rurales).

Si nous considérons important de récupérer et mettre en pratique les savoirs agroécologiques concernant les maïs natifs, les échanges de matériel génétique sous le contrôle des agriculteurs eux-mêmes, les symboles et signifiants que les maïs peuvent forger dans une identité communautaire, il serait toutefois nécessaire de dessiner, d'une part, une politique agricole nationale qui renforcerait la recherche sur les potentialités des maïs natifs. D'autre part, il faudrait construire différentes politiques agricoles, en prenant en compte les conditions environnementales et sociales, qui ferait la promotion de la culture d'une agro-biodiversité aux mains des petits et moyens producteurs pour leur bien-être social et la construction progressive de leur souveraineté alimentaire. Lutter pour une hausse des prix des maïs natifs à travers le développement de marchés "gourmet» n'est pas suffisant, il faut demander la reconnaissance et la valorisation culturelle, sociale et de l'identité communautaire des maïs. Il ne suffit pas d'introduire les maïs natifs dans une niche des marchés, si la partie inaliénable du patrimoine bio-culturel des maïs ne s'hérite plus des générations passées 
avec des valeurs intangibles qui moulent l'identité et l'appartenance à un territoire caractérisé par son patrimoine bio-culturel.

Nous remercions vivement l'invitation, le soutien financier et logistique de CONABIO pour participer au projet Proyecto Global de Maíces Nativos. Particulièrement, l'appui de Dr. Francisca Acevedo et M. Oswaldo Oliveros a été très précieux. Également, nous voudrions remercier Marianna Fenzi et Catherine Hoare pour leurs révisions méticuleuses.

\section{BIBLIOGRAPHIE}

Akpan N. 2017 - Wetlands stopped \$625 million in property damage during Hurricane Sandy. Can they help Houston? PBS Newshour, Aug 31, 2017. [En ligne] http://www.pbs.org/newshour/ updates/wetlands-stopped-650-million-property-damage-hurricane-sandy-can-help-houston/

Anderson E. 1947 - Field studies of Guatemalan maize. Ann. Mo. Bot. Gard. 34 : 433-451.

Aragón-Cuevas F. 2010 - Razas de maíz en Oaxaca [Video]. Oaxaca : SAGARPA, INIFAP, SNICS, SINAREFI.

Argumedo [s.d.] Territorios Bioculturales Indígenas. Propuesta para la protección de territorios indígenas y el Buen Vivir. Asociación ANDES. [En ligne] http://www.internationalfunders.org/documents/ TerritoriosBioculturalesIndigenas.pdf

Azuela de la Cueva A. 2009 - Durkheim y la tentación contractualista. Notas sobre la dimensión mítica del patrimonio nacional de México. In : Geneyro J.C., Azuela A. \& Marín J.C. ¿Por qué leer a Durkheim hoy? México, Ed. Fontamara : 50-79.

Bellon M. 1991 - The Ethnoecology of Maize Variety Management: A Case Study from Mexico. Human Ecology 19 (3) : 389-418.

Bellon M., Mastretta A., Ponce A., Ortíz D., Oliveros O., Perales H., Acevedo F. \& Sarukhán, J. 2018 - Evolutionary and food supply implications of ongoing maize domestication by Mexican campesinos. Proc. R. Soc. B 285 : 20181049. http://dx.doi.org/10.1098/ rspb.2018.1049

Benz B.F, Perales H. \& Brush S. 2007 - Tzeltal and Tzotzil farmer knowledge and maize diversity in Chiapas, Mexico. Curr. Anthropol. 48 (2) : 289-200.

Bertran M. 2005 - Cambio alimentario e identidad de los indígenas mexicanos. México, Ed. UNAM.

Boege E. 2008 - El Patrimonio Biocultural de los Pueblos Indígenas de México. Hacia la conservación in situ de la biodiversidad y agrodiversidad en los territorios indígenas. México, Ed. INAH / CDI.

Boyd J. \& Banzhaf S. 2007 - What Are Ecosystem Services? The Need for Standardized Environmental Accounting Units. Ecological Economics 63 : 616-626.

Brush S. 1986 - Genetic diversity and conservation in traditional farming systems. Journal of Ethnobiology 6 (1) : 151-167.

Brush S., Bellon M. \& Schmidt E. 1988 - Agricultural development and maize diversity in Mexico. Human Ecology 16 (3) : 307-328. 
Camou E. 2008 - Nutrir la persona, nutrir la identidad. Reflexiones filosóficas sobre antropología y cultura alimentaria. In : Sandoval S. \& Meléndez M. Cultura y seguridad alimentaria. México, Ed. CIAD/ Plaza et Valdés : 19-36.

Carrillo A. 2013 - Sistema agrícola milpa de Chiapas avanza hacia su reconocimiento como Patrimonio Cultural de la Humanidad. Red Maíz Criollo Chiapas. [En ligne] http://redmaizchiapas.blogspot.ch/ search/label/La\%20Milpa\%20es\%20Patrimonio\%20Cultural

Casas A., Viveros J.L., Katz E. \& Caballero J. 1987 - Las plantas en la alimentación mixteca: Una aproximación etnobotánica. América Indígena. 47 (2) : 317-343.

Casas A., Blancas J., Pérez E., Torres-García I., Vallejo M., Rangel S., Moreno A. \& Farfán B. 2014 Manejo sustentable de recursos naturales: Naturaleza y cultura. In : Arias G. et al. (Ed.). Sustentabilidad e Interculturalidad. Paradigmas entre la relación cultura y naturaleza. Pátzcuaro, Universidad Intercultural Indígena de Michoacán : 10-20.

Celestino Solís E. 2004 - Gotas de maíz. Jerarquía de cargos y ritual agrícola en San Juan Tetelcingo, Guerrero. México, D.F., CIESAS. (Antropología).

Centro de investigaciones agrarias edición del 25 aniversario 1954/1979 1980 - El cultivo del maíz en México. México.

Collier G.1992 - Búsqueda de alimentos y búsqueda de dinero: Cambios en las relaciones de producción en Zinacantan, Chiapas. In : Hewitt de Alcantara C. (Ed.) Reestructuración económica y subsistencia rural. El maíz y la crisis de los ochenta. México, El colegio de México Centro Tepoztlán, Instituto de Investigaciones de las Naciones Unidas para el Desarrollo Social : 183-22.

CONABIO 2010 - Proyecto global de maíces nativos. Informe.

CONABIO 2011 - Proyecto Global de Maíces Nativos. Comisión Nacional para el Conocimiento y Uso de la Biodiversidad; Instituto Nacional de Investigaciones Forestales, Agrícolas y Pecuarias; Instituto Nacional de Ecología y cambio Climático. México [En ligne] http:// www.biodiversidad.gob.mx/genes/proyectoMaices.html

Contreras J. 2008 - Modernidad alimentaria: entre la sobreabundancia y la inseguridad. In : Sandoval S. \& Meléndez M. Cultura y seguridad alimentaria. México, Ed. CIAD/ Plaza y Valdés : 53-80.

Costanza R. \& Daly H. 1992 - Natural Capital and Sustainable Development. Conservation Biology 6 (1) : $37-46$

Costanza R., d'Arge R., De Groot R., Farber S., Grasso M., Hannon B., Naeem S., Limburg K., Paruelo J., O'Neill R.V., Raskin R.G., Sutton P. \& Van den Belt M. 1997 - The value of world's ecosystem services and natural capital. Nature 387 (15) : 253-260.

Daily G.C. 1997 - Nature's services: societal dependence on natural ecosystems. Washington D.C., Island Press.

Dyer G.A., López-Feldman A., Yúnez-Naude A. \& Taylor J.E. 2014 - Genetic erosion in maize’s center of origin. Proc Natl Acad Sci USA 111 (39) :14094-14099.

Ellen R. \& Fukui K. 1996 - Redefining nature. Ecology, culture and domestication. Oxford, Berg Ed.

ENA (Encuesta Nacional Agropecuaria) 2017 - Resultados de la encuesta nacional agropecuaria. México. [En ligne] https://datos.gob.mx/busca/dataset/encuesta-nacional-agropecuaria-ena Esteva G. 2003 - Los árboles de las culturas mexicanas. In : Esteva G. y Marielle C. (Ed.) Sin maíz no hay país. México, Ed. CONACULTA : 17-35. 
Fenzi M. 2017 - «Provincialiser » la Révolution Verte : savoirs, politiques et pratiques de la conservation de la biodiversité cultivée (1943-2015). Thèse Doctorat en Histoire des sciences, École des Hautes Études en Sciences Sociales, Paris, France.

Fenzi M. \& Bonneuil C. 2016 - Genetic Resources » to « Ecosystems Services »: A century of Science and Global Policies for Crop Diversity Conservation. Culture, Agriculture, Food and Environment 38 (2) : 72-83.

Fernández R., Morales L. \& Gálvez A. 2013 - Importancia de los maíces nativos de México en la dieta nacional. Una revisión indispensable. Revista Fitotecnia Mexicana 36, Supl. 3-A : 275-283.

Ferry E. 2002 - Inalienable Commodities: The Production and Circulation of Silver and Patrimony in a Mexican Mining Cooperative. Cultural Anthropology 17 (3) : 331-358.

Gadgil M., Berkes F. \& Folke C. 1993 - Indigenous knowledge for biodiversity conservation. Ambio $22: 151-156$.

García-Barrios L. \& García-Barrios R. 1992 - La modernización de la pobreza: dinámicas de cambio técnico entre los campesinos temporaleros de México. Rev. Estudios Sociológicos 10 (29) : 263-288.

Geertz C. 1995 La interpretación de las culturas. Barcelona, Gedisa.

Gómez-Baggethun E. \& de Groot R. 2007 - Capital natural y funciones de los ecosistemas: explorando las bases ecológicas de la economía. Ecosistemas 16 (3) : 4-14.

González M. 2009 - Xala un pueblo, un destino. México, Ed. Casa de la Cultura de Xala/PACMETC., 358 p.

Gudynas E. 2000 - Los límites de la sustentabilidad débil y el tránsito desde el capital natural al patrimonio ecológico. Educación, Participación et Ambiente 4 (11) : 7-11.

Hernandez-Xolocotzi E. 1959 - La Agricultura. In : Beltrán E. (Ed.) Los recursos naturales del sureste y su aprovechamiento. México, Inst. Mex. Rec. Nat. Renov. : Tomo II, Capítulo I.

Hernández-Xolocotzi E. 1985 - Maize and the greater southwest. Economic Botany 39 (4) : 416-430.

Hewitt de Alcantara C. 1992 - Introducción, Reestructuración económica y subsistencia rural. In : Hewitt de Alcantara C. (Ed.) Reestructuración económica y subsistencia rural. El maíz y la crisis de los ochenta. México, El colegio de México Centro Tepoztlán, Instituto de Investigaciones de las Naciones Unidas para el Desarrollo Social : 15-62.

Houtart F. 2014 - El concepto de sumac kawsay (Buen Vivir) y su correspondencia con el bien comun de la humanidad. In : Delgado G.C. Buena Vida, Buen Vivir: Imaginarios alternativos para el bien común de la humanidad. México, Ed. CEIICH, UNAM.

Howes M. \& Chambers R. 1980 - Indigenous technical knowledge: Analysis, implications and issues. In : Brokensha D., Warren D.W. \& Werner O. (Ed.) Indigenous Knowledge Systems and Development. Washington D.C., Univ of America : 335-351.

INEGI 2018 - Encuesta Nacional de Ingresos y Gastos de los Hogares.

Ingold T. 1992 - Culture and the perception of the environment. In : Croll E. \& Parkin D. (Ed.), Bush base : forest farm. Culture, environment and development. Londres, Routledge : 39-56.

Kato Y. T.A., Mapes S. C., Mera O. L.M., J.A. Serratos H. R.A. \& Bye Boettler R.A. 2009 - Origen y diversificación del maíz: una revisión analítica. México, UNAM, Comisión Nacional para el Conocimiento y Uso de la Biodiversidad : 116. 
Katz E. 1996 - La influencia del contacto en la comida campesina mixteca. In : Long J. (Ed.), Conquista et comida: consecuencias del encuentro de dos mundos. México, Universidad Nacional Autónoma de México : 339-363.

Lazos E. 2008 - La fragilidad de la biodiversidad: Semillas y suelos entre una conservación y un desarrollo empobrecido. In : Seefoó J.L. (Ed.), Desde los colores del maíz: Una agenda para el campo mexicano. Zamora, Michoacán, Ed. El Colegio de Michoacán : 457-487.

Lazos E. 2011 - Tiempo de maíz: tiempo de ayer y de mañana. In : Reyes Escutia F. \& Barrasa García S. (Ed.), Saberes ambientales campesinos. Cultura y naturaleza en comunidades indígenas y mestizas de México. Tuxtla Gutiérrez, Chiapas: UNICACH / Univ. Autónoma de Madrid : 61-95. (Jaguar).

Lazos E. 2013 - Resistencias de las sociedades campesinas: ¿control sobre la agrodiversidad y la riqueza genética de sus maíces? In : Padilla T. (Ed.) El Campesinado y su persistencia en la actualidad mexicana. México, Ed. Conaculta y Fondo de Cultura Económica : 391-427.

Lazos E. \& Chauvet M. 2012 - Análisis del contexto social y biocultural de las colectas de maíces nativos en México. Proyecto global de maíces nativos. Primer informe.

Lele S., Springate-Baginski O., Lakerveld R., Deb D. \& Dash P. 2013- Ecosytstem Services: Origins, Contributions, Pitfalls, and Alternatives. Conservation and Society 11 (4) : 343-358.

Lévi-Strauss C. 1965 - Le triangle culinaire. L'Arc $26: 22-29$.

López Austin A. 1992 - Los mitos del tlacuache. Caminos de la mitología mesoamericana. México, Alianza editorial mexicana.

Mapes C. 1987 - El maíz entre los Purépechas de la cuenca del Lago de Pátzcuaro, Michoacán, México. América Indígena 47 (2) : 345-379.

Mauss M. 1990 [1950] - The Gift: The Form and the Reason for Exchange in Archaic Societies. New York, W.W. Norton.

Mestries F. 2002 - El rancho se nos llenó de viejos: crisis del agro y migración internacional en Zacatecas. México, Universidad de Zacatecas y Plaza y Valdes.

Montañez C. \& Aburto H. 1979 - Maíz, política institucional y crisis agrícola. México, CIDER. Nueva Imagen : 249.

Morales L.D., Vizcarra I., Thomé Ortiz H. \& Arteaga T. 2017 - El marco jurídico en defensa del maíz nativo. ¿Y la agricultura familiar campesina? Un análisis desde la perspectiva de productores. In : Gómez W., Thomé Ortiz H. (Ed.) Estudios de caso sobre ciencias agropecuarias y rurales en el siglo XXI. Ciudad de México, Colofón; Estado de México, Universidad Autónoma del Estado de México : 191-206.

Nadal A. \& Wise T. 2005 - Los costos ambientales de la liberalización agrícola: el comercio de maíz entre México y EE.UU. en el marco del NAFTA. In : Blanco H., Togeiro L. \& Gallagher K. (Ed.), Globalización y Medio Ambiente: Lecciones desde las Américas. Santiago de Chile, RIDES-GDAE . 49-92.

Orozco Q., Barrera N., Astier M. \& Masera O. 2010 - El sistema maíz-tortilla en el estado de Michoacán. In : Seefó J.L. \& Keilbach N. Ciencia y paciencia campesina. El maíz en Michoacán. El Colegio de Michoacán/ Secretaría de Desarrollo Rural, Gobierno del Estado de Michoacán : 119-136.

Ortega-Paczka R. 2003 - La diversidad del maíz en México. In : Esteva G. \& Marielle C. (Ed.) Sin maíz no hay país. México,vEd. CONACULTA : 123-155. 
Ortega M.I., Alcalá G. 2008 - Pobreza, migración y seguridad alimentaria. In : Sandoval S.A. \& Meléndez M. (Ed.), Cultura y seguridad alimentaria, enfoques conceptuales, contexto global y experiencias locales. México, Plaza y Valdez : 177-194.

Oseguera D. 2010 - Las huellas del maíz en la cocina michoacana. In : Seefoó J.L. \& Keilbach N., Ciencia y paciencia campesina. El maíz en Michoacán. Gobierno del Estado de Michoacán, El Colegio de Michoacán/ Secretaría de Desarrollo : 193-222.

Oseguera D. 2008 - En las fronteras de la inseguridad alimentaria: subjetividad en familias michoacanas. In : Sandoval Godo S.A. \& Meléndez M. (Ed.), Cultura y Seguridad Alimentaria; Enfoques conceptuales, contexto global et experiencias locales. México, Plaza et Valdez : 153-176.

Palacios O., Ortega A., Guerrero M., Hernández J.M., Alberto L. 2008 - Diversidad y distribución actual de los maíces nativos en Sinaloa. Informe final de actividades 2007-2008. CONABIO/INIFAP, $100 \mathrm{p}$.

Perales M. 2010 - Los campesinos de Cantabria, ¿hombres de maíz? In : Seefóo J.L. \& Keilbach N.M. (Ed.) 2010 - Ciencia y paciencia campesina, El maíz en Michoacán. El Colegio de Michoacán : 161-191.

Perales H. \& Golicher D. 2014 - Mapping the diversity of maize races in Mexico. PLoS ONE 9 (12) : $1-20$.

Perales H., Stephen B. \& Qualsy C.O. 2003 - Landraces of Maize in Central Mexico: an altitudinal transect. Economic Botany 57 : 7-20.

Pérez Ruiz M.L. 2018 - La milpa como patrimonio biocultural. In : Peña Y. \& Hernández L. Biodiversidad, patrimonio y cocinas. México, Inst. Nacional de Antropología e Historia : 215-236.

Piñeyro-Nelson A., Heerwaarden J., Perales H.R., Serratos J.A., Rangel A., Hufford M.B., Gepts P., Garay-Arroyo A., Rivera-Bustamante R., Álvarez-Buylla E. 2009 - Transgenes in Mexican maize: molecular evidence and methodological considerations for gmo detection in landrace populations. Molecular Ecology 18 (4) : 750-761.

Quist D. \& Chapela I. 2001 - Transgenic DNA introgressed into traditional maize landraces in Oaxaca, Mexico. Nature 414 : 541-543.

Ramírez A. 2012 - Caracterización socioeconómica, morfológica y bioquímica de una muestra etnográfica de maíz (Zea mays L.) Raza Bolita. Tesis de doctorado, Colegio de Postgraduados, Montecillo, Texcoco, $240 \mathrm{p}$.

Ramos A. 2003 - El valor e significado de los saberes tradicionales. In : Esteva G. \& Marielle C. (Ed.) Sin maíz no hay país. México, CONACULTA : 251-258.

Ribeiro D. 1990 - Cultura y enajenación. In : Zemmelman H. Cultura y política en América Latina. México, Ed. Siglo XXI/UNU.

Rist S. 2002 - Si estamos de buen corazón, siempre hay producción. Caminos en la renovación de formas de producción y vida tradicional y su importancia para el desarrollo sostenible. Bolivia, Ed. AGRUCO, Plural Ed. CDC.

Robles Berlanga H. 2016 - La pequeña agricultura campesina y familiar: Construyendo una propuesta desde la sociedad. EntreDiversidades Revista de Ciencias Sociales e Humanidades 7 : 46-83.

Sandstrom A 2010 - El maíz es nuestra sangre. Cultura e identidad étnica en un pueblo indio azteca contemporáneo. CIESAS/ Secretaría de Cultura, SLP/El Colegio de San Luis.

Sarukhan J. 2008 - Capital natural de México. Conocimiento actual de la biodiversidad. Vol. 1. México, Comisión nacional para el conocimiento y uso de la biodiversidad. 
Seefóo J.L. \& Keilbach N.M. (Ed.) 2010 - Ciencia y paciencia campesina, El maíz en Michoacán. El colegio de Michoacán, $287 \mathrm{p}$.

Sevilla A. 2017 - Los derechos culturales en el marco de los actuales procesos de patrimonialización de la UNESCO. Diario de Campo, cuarta época, año 1, núm. enero- abril : 111-122.

Sherwood S., Arce A. \& Paredes M. 2017 - Food, Agriculture and Social Change. The Everyday Vitality of Latin America. Oxon/ N.York, Earthscan, Routledge.

SIAP 2016 - https://www.gob.mx/siap

Silva D. 2017 - Protecting the vital: Analysing the relationship between agricultural biosafety and the commodification of genetically modified cotton seeds in Colombia. Tesis doctoral. The Graduate Institute of Geneva.

Suarez V. 2013 - ¿Cómo podemos alcanzar la autosuficiencia alimentaria ? Nueva revolución tecnológica con campesinos y sin transgénicos. Suplemento Informativo de La Jornada 65.

Taba S. (Ed.) 1995 - Maize Genetic Resources. Maize Program Special Report: Latin America Maiz Germoplasm Regeneration and Conservation. Mexico, CIMMETT.

Terán S. \& Rasmussen C. 1994 - La milpa de los mayas prehispánicos y actuales. México, Ed. Danida, Warman A. 1988 - La historia de un bastardo: maíz y capitalismo. México, FCE : 281.

Warman A. \& Montañez C. (Ed.) 1982 - El cultivo del maíz en México, diversidad, limitaciones y alternativas. Seis estudios de caso. México, Centro de Ecodesarrollo.

Weiner A. 1992 - Inalienable Possessions: The Paradox of Keeping-While-Giving. Berkeley, University of California Press.

Weismantel M. 1994 - Alimentación, género y pobreza en los andes ecuatorianos. Ecuador, Biblioteca Abya-Yala.

Wellhausen E.J., Roberts L.M., Hernández E.X. \& Mangelsdorf P.C. (Coll.) 1951 - Razas de maíz en México. Su origen, características y distribución. México D. F., OEE-SAG. Folleto No.5. 236 p.

Wise T. 2005 - Identifying the Real Winners from US Agricultural Policies. Medford, Tufts University. Global Development and Environment Institute Working Paper 05-07.

Wise T.A. 2007 - Policy Space for Mexican Maize: Protecting Agro-biodiversity bet Promoting Rural Livelihoods. GDAE Working Paper No. 07-01., Meadford MA, USA. Tufts University.

\section{NOTES}

1. La milpa, système agricole particulier au Mexique, qui peut associer différentes variétés de maïs avec des variétés d'haricots et des courges étalant leurs larges feuilles à leur pied, maintenant ainsi fraîcheur et humidité. Selon la région, d'autres cultures peuvent être associées, comme des variétés de piments, de tomates (verts ou à l'état sauvage), d'autres cucurbitacées, des tubercules (la patate douce, les ignames) et des plantes à l'état sauvage ou semi-domestiqués comme les quelites (Amaranthus spp et d'autres espèces, voir www.biodiversidad.gob.mx/ diversidad/alimentos/quelites). Même des arbres fruitiers peuvent être intercalés.

2. Ceci signifie que la formation des prix ne se détermine plus sur les processus fondamentaux du marché agricole (offre, demande, réserves) mais sur des facteurs extra sectoriels. Cela a provoqué déjà une hausse des prix des produits agricoles soumis à une extrême volatilité des marchés. Et la spéculation internationale, l'instabilité économique globale, le pouvoir croissant des 
corporations agroalimentaires sur le contrôle des marchés menace gravement la production familiale paysanne.

3. Depuis les années 60 , le terme de « ressources génétiques » est devenu un point important au niveau international, notamment pour la FAO, mais également dans le processus de marchandisation privée de la semence menée par les gouvernements. La gestion de l'agrodiversité accompagne parallèlement le développement agroindustriel (Fenzi et Bonneuil 2016).

4. Un des objectifs du «Projet Global des Maïs Natifs» de la CONABIO est de déterminer la distribution géographique des maïs natifs afin de reconnaître l'ensemble du territoire mexicain comme centre d'origine et de diversification du maïs.

5. Citation originale: "it would be very easy to conduct intense exploitation, but the modernization would not allow the source of jobs to last for long» (Ferry $2002: 339$ ) traduction des auteures.

6. Le Totopo de Oaxaca est un type de tortilla de maïs légèrement grillée, ronde et de diamètre compris entre 20 et $25 \mathrm{~cm}$ (elles sont commercialisées sous forme de triangles, mais elles sont originellement rondes comme des tortillas d'un diamètre plus grand).

7. Emphase de l'auteur.

8. Composée de la Commission nationale pour le développement des Peuples Indigènes, la Commission nationale des Cultures Populaires de Conaculta, l'Institut National d'Anthropologie et d'Histoire, l'Institut National des Langues Indigènes et l'Institut National des Beaux-Arts.

9. Les solares sont des jardins familiaux autour les maisons des familles paysannes. Le conuco est un système maraîcher de productivité élevée qui fait partie du système de milpa maya au Yucatán. Le pach pakal sont de petites aires dédiées à la culture des légumes, des tubercules et des fruits dans les milpas mayas.

10. Par exemple, le maïs Bolita pour la confection des tlayudas revient plus cher que les maïs hybrides apportés de Sinaloa ou Puebla, ce qui, si on généralise, peut amener à éliminer les maïs natifs dans la confection de produits ou plats de la cuisine régionale.

11. Connu également comme « Recueil, production, actualisation et analyses de l'information sur la diversité génétique des maïs natifs et leurs parents sauvages au Mexique ». Il avait pour objectif d'actualiser l'information sur les maïs natifs et leurs parents sauvages au Mexique pour la détermination des centres de diversité génétique du maïs.

12. Assurément, la configuration des données serait différente si, au nord, on avait analysé les trois régions (nord-est, nord-centre et nord-ouest). Cependant, les données ne sont pas suffisantes pour cette analyse. De même, le centre pourrait se distinguer bien plus, mais on a voulu faire ressortir que quelques contrastes. Cependant, une étude plus minutieuse par régions donnerait d'autres hypothèses de travail qui seraient importantes pour mieux comprendre.

13. Dans ce chapitre, tous les pourcentages se réfèrent aux collectes additionnées par région : au nord, ce sont 1933, au centre, 2904 et au sud 3113. C'est pourquoi nous ne pouvons pas additionner les pourcentages régionaux puisqu'ils correspondent à des univers différents.

14. Certaines races ont toujours présenté une distribution restreinte lors de l'analyse des collectes (Perales \& Golicher 2014). Cependant, d'autres races présentent une réduction de sa distribution (Chiquito, Xala, Olotón, Palomero, Toluqueño, Zapalote Chico) alors que d'autres encore ont tellement diminué qu'on peut les considérer menacées (Chapalote, Complejo Serrano de Jalisco, Dulcillo del Noreste, Xala, Onaveño, Tablilla de Ocho) (Perales et Golicher 2014). Depuis les années 60, les sélectionneurs de plantes considèrent l'« érosion génétique » comme « la partie inévitable du développement économique et sociale » et présentent la substitution des variétés locales par des variétés améliorées comme un processus inéluctable (Fenzi et Bonneuil 2016). Toutefois, dans le cas du Mexique, cette affirmation a été sérieusement remise en question (Perales \& Golicher 2014, Fenzi et al. 2015, Fenzi \& Bonneuil 2016).

15. Les Raramuri habitent dans l'état de Chihuahua au nord du Mexique.

16. Elotes sont les épis de maïs frais. 
17. Ces données doivent être prises avec précaution puisque, dans les études de niveau micro, presque toutes les familles paysannes utilisent leur production aussi bien pour l'autoconsommation que pour le marché (Bellon 1991, Lazos 2011, Lazos 2013, Bellon 2018).

18. Le nombre de producteurs varie pour chaque variable analysée parce qu'il répond au nombre d'enquêtes complètes dans cette rubrique.

19. Minifundisme - petites surfaces de terres cultivées par une famille paysanne.

\section{RÉSUMÉS}

Les maïs natifs sont le patrimoine bio-culturel des paysans indigènes et métis de tout le pays. Leur culture, du fait des conditions agroécologiques et climatiques spécifiques, est source de processus identitaires intercommunautaires. Le maïs fait partie de la culture alimentaire du paysan mexicain, de son appartenance historique et communautaire ainsi que les valeurs et les symboles partagés qui s'y rattachent. Dans cet article, seront discutées les caractéristiques aliénables et inaliénables du maïs et la vulnérabilité de ce binôme, pour rehausser son importance dans la création de la biodiversité des maïs natifs. Dans le but de reconnaitre que tout le territoire national est centre d'origine et de diversification du maïs, un parcours de la diversité des mosaïques agricoles dans le nord, le centre et le sud du pays a été effectué. Finalement, on démontre les risques de concevoir les maïs uniquement comme capital naturel.

Maize landraces constitute the biocultural heritage of indigenous and mestizo peasants throughout the country. Its cultivation, conditioned by the climatic and agro-ecological environment, contributes to shape identities among communities. Maize is part of their food culture, of their historical legacy at the community level and of their shared meanings and symbols. The article discusses the alienable and inalienable characteristics of maize and the vulnerability of this binomial. The aim is to emphasize the importance of promoting maize biodiversity. This article traverses different agricultural mosaics between the north, south and center of the country in order to recognize that the entire national territory is the center of origin and diversification of maize. Finally, it warns about the risks of conceiving maize as a natural capital.

Los maíces nativos constituyen el patrimonio biocultural de campesinos indígenas y mestizos en todo el país. Su cultivo, condicionado por el entorno climático y agroecológico, conforma procesos identitarios entre las comunidades. El maíz forma parte de su cultura alimentaria, de su sentir histórico-comunitario y de los significados y símbolos compartidos. En el artículo se discuten las características alienables e inalienables del maíz y la vulnerabilidad de este binomio, para enfatizar la importancia de fomentar la biodiversidad de los maíces nativos. Se hace un recorrido por la diversidad de mosaicos agrícolas entre el norte, sur y centro del país con el propósito de reconocer que todo el territorio nacional es centro de origen y diversificación del maíz. Finalmente, se advierte sobre los riesgos de concebir a los maíces como capital natural. 
INDEX

Keywords : maize landraces, biocultural heritage, food culture, agrobiodiversity and maize regions

Mots-clés : maïs natifs, patrimoine bio-culturel, culture alimentaire, agrodiversité, régions de culture de maïs

Palabras claves : maíces nativos, patrimonio biocultural, cultura alimentaria, agrobiodiversidad y regiones maiceras

Index géographique : Mexique

\section{AUTEURS}

\section{ELENA LAZOS-CHAVERO}

Instituto de Investigaciones Sociales, Universidad Nacional Autónoma de México

\section{MICHELLE CHAUVET}

Universidad Autónoma Metropolitana, Azcapotzalco 